\title{
Concordance between the diagnostic guidelines for alcohol and cannabis use disorders in the draft ICD-11 and other classification systems: Analysis of data from the WHO's World Mental Health Surveys
}

\section{Louisa Degenhardt, Chrianna Bharat, Raimondo Bruno, Meyer D. Glantz, Nancy A. Sampson, Sergio} Aguilar-Gaxiola, Jordi Alonso, Laura Helena Andrade, Brendan Bunting, Jose Miguel Caldas-de-Almeida, Alfredo H. Cia, Oye Gureje, Elie G. Karam, Mohammad Khalaf, John McGrath, Jacek Moskalewicz, Sing Lee, Zeina Mneimneh, Fernando Navarro-Mateu, Carmen C. Sasu, Kate Scott, Yolanda Torres, Vladimir Poznyak, Somnath Chatterji and Ronald C. Kessler, on behalf of the WHO World Mental Health Survey Collaborators*.

Bold = core group

Running head: ICD-11 substance use disorder concordance

Word Count: 5097

Corresponding author: Louisa Degenhardt

l.degenhardt@unsw.edu.au

National Drug and Alcohol Research Centre

UNSW Sydney, Sydney, Australia

Declaration of Interests: In the past three years, LD has received investigator-initiated untied educational grants for studies of opioid medications in Australia from Indivior, Mundipharma and Seqirus. RK received support for his epidemiological studies from Sanofi Aventis; was a consultant for Johnson \& Johnson Wellness and Prevention, Shire, Takeda; and served on an advisory board for the Johnson \& Johnson Services Inc. Lake Nona Life Project. RK is a co-owner of DataStat, Inc., a market research firm that carries out healthcare

This is the author manuscript accepted for publication and has undergone full peer review but has not been through the copyediting, typesetting, pagination and proofreading process, which may lead to differences between this version and the Version of Record. Please cite this article as doi: $10.1111 /$ add.14482 
research. VP is a staff member of the World Health Organization involved in the development and field testing of ICD-11 for disorders due to substance use and addictive behaviours. SC is also a staff member of the World Health Organization. MG's role on this study is through his involvement as a Science Officer on U01MH60220. He had no involvement in the other cited grants. All other authors declare no competing interests. 
Louisa Degenhardt, PhD, National Drug and Alcohol Research Centre (NDARC), UNSW Sydney, Australia; Chrianna Bharat, BSc(Hons.), National Drug and Alcohol Research Centre (NDARC), UNSW Sydney, Australia; Raimondo Bruno, PhD, School of Medicine, University of Tasmania, Hobart, Australia; Meyer D. Glantz, PhD, Department of Epidemiology, Services, and Prevention Research (DESPR), National Institute on Drug Abuse (NIDA), National Institute of Health (NIH), Bethesda, Maryland, USA; Nancy A. Sampson, BA, Department of Health Care Policy, Harvard Medical School, Boston, Massachusetts, USA; Sergio AguilarGaxiola, MD, PhD, Center for Reducing Health Disparities, UC Davis Health System, Sacramento, California, USA; Jordi Alonso, MD, PhD, Health Services Research Unit, IMIM-Hospital del Mar Medical Research Institute, Barcelona, Spain; CIBER en Epidemiología y Salud Pública (CIBERESP), Spain; Pompeu Fabra University (UPF), Barcelona, Spain; Laura Helena Andrade, MD, PhD, "Núcleo de Epidemiologia Psiquiátrica - LIM 23, Instituto de Psiquiatria Hospital das Clinicas da Faculdade de Medicina da Universidade de São Paulo, Brazil; Brendan Bunting, PhD, School of Psychology, Ulster University, Londonderry, United Kingdom; Jose Miguel Caldas-de-Almeida, MD, PhD, Lisbon Institute of Global Mental Health and Chronic Diseases Research Center (CEDOC), NOVA Medical School | Faculdade de Ciências Médicas, Universidade Nova de Lisboa, Lisbon, Portugal; Alfredo H. Cia, MD, Anxiety Disorders Center, Buenos Aires, Argentina; Oye Gureje, MD, PhD, FRCPsych, Department of Psychiatry, University College Hospital, Ibadan, Nigeria; Elie G. Karam, MD, Department of Psychiatry and Clinical Psychology, Faculty of Medicine, Balamand University, Beirut, Lebanon; Department of Psychiatry and Clinical Psychology, St George Hospital University Medical Center, Beirut, Lebanon; Institute for Development Research Advocacy and Applied Care (IDRAAC), Beirut, Lebanon; Mohammad Khalaf, MD, Ibn Sina Teaching Hospital, Alshifaa, Mosul, Iraq; John McGrath, MD, PhD, Queensland Centre for Mental Health Research, The Park Centre for Mental Health, Wacol, Australia, Queensland Brain Institute, The University of Queensland, St Lucia, Australia, National Centre for Register-based Research, Aarhus University, Aarhus, Denmark; Jacek Moskalewicz, MD, PhD, Institute of Psychiatry and Neurology, Warsaw, Poland; Sing Lee, MB, BS, Department of Psychiatry, Chinese University of Hong Kong, Tai Po, Hong Kong; Zeina Mneimneh, PhD, Survey Research Center, Institute for Social Research, University of Michigan, Ann Arbor, Michigan, USA; Fernando Navarro-Mateu, MD, PhD, UDIF-SM, Subdirección General de Planificación, Innovación y Cronicidad, Servicio Murciano de 
Salud. IMIB-Arrixaca. CIBERESP-Murcia, Murcia, Spain; Carmen C. Sasu, MD, National School of Public Health, Management and Professional Development Bucharest, Romania; Kate Scott, PhD, Department of Psychological Medicine, University of Otago, Dunedin, Otago, New Zealand; Yolanda Torres, MPH, Dra.HC Center for Excellence on Research in Mental Health, CES University, Medellin, Colombia; Vladimir Poznyak, MD, Department of Mental Health and Substance Abuse, World Health Organization, Geneva, Switzerland; Somnath Chatterji, MD, Department of Information, Evidence and Research, World Health Organization, Geneva, Switzerland; Ronald C. Kessler, PhD, Department of Health Care Policy, Harvard Medical School, Boston, Massachusetts, USA;

* The WHO World Mental Health Survey collaborators are Sergio Aguilar-Gaxiola, MD, PhD, Ali AlHamzawi, MD, Mohammed Salih Al-Kaisy, MD, Jordi Alonso, MD, PhD, Laura Helena Andrade, MD, PhD, Corina Benjet, PhD, Guilherme Borges, ScD, Evelyn J. Bromet, PhD, Ronny Bruffaerts, PhD, Brendan Bunting, $\mathrm{PhD}$, Jose Miguel Caldas de Almeida, MD, PhD, Graça Cardoso, MD, PhD, Somnath Chatterji, MD, Alfredo H. Cia, MD, Louisa Degenhardt, PhD, Koen Demyttenaere, MD, PhD, John Fayyad, MD, Silvia Florescu, MD, $\mathrm{PhD}$, Giovanni de Girolamo, MD, Oye Gureje, MD, DSc, FRCPsych, Josep Maria Haro, MD, PhD, Yanling He, MD, Hristo Hinkov, MD, PhD, Chi-yi Hu, MD, PhD, Yueqin Huang, MD, MPH, PhD, Peter de Jonge, PhD, Aimee Nasser Karam, PhD, Elie G. Karam, MD, Norito Kawakami, MD, DMSc, Ronald C. Kessler, PhD, Andrzej Kiejna, MD, PhD, Viviane Kovess-Masfety, MD, PhD, Sing Lee, MB, BS, Jean-Pierre Lepine, MD, Daphna Levinson, PhD, John McGrath, MD, PhD, Maria Elena Medina-Mora, PhD, Zeina Mneimneh, PhD, Jacek Moskalewicz, PhD, Fernando Navarro-Mateu, MD, PhD, Beth-Ellen Pennell, MA, Marina Piazza, MPH, ScD, Jose Posada-Villa, MD, Kate M. Scott, PhD, Tim Slade, PhD, Juan Carlos Stagnaro, MD, PhD, Dan J. Stein, FRCPC, PhD, Margreet ten Have, PhD, Yolanda Torres, MPH, Dra.HC, Maria Carmen Viana, MD, PhD, Harvey Whiteford, MBBS, PhD, David R. Williams, MPH, PhD, Bogdan Wojtyniak, ScD. 


\begin{abstract}
Background and aims: The World Health Organization's (WHO's) proposed International Classification of Diseases, 11th Edition (ICD-11) includes several major revisions to substance use disorder (SUD) diagnoses. It is essential to ensure the consistency of within-subject diagnostic findings across countries, languages and cultures. To date, agreement analyses between different SUD diagnostic systems have largely been based in high-income countries and clinical samples rather than general population samples. We aimed to evaluate the prevalence of, and concordance between diagnoses using the ICD-11, The WHO's ICD $10^{\text {th }}$ Edition (ICD-10), and the Diagnostic and Statistical Manual of Mental Disorders, $4^{\text {th }}$ and $5^{\text {th }}$ editions (DSM-IV, DSM-5); prevalence of disaggregated ICD-10 and ICD-11 symptoms; and variation in clinical features across diagnostic groups.

Design: Face-to-face household surveys.

Setting: Representative surveys of the general population in ten countries (Argentina, Australia, Brazil, Colombia, Iraq, Northern Ireland, Poland, Portugal, Romania and Spain) of the World Mental Health Survey Initiative.
\end{abstract}

Participants: Questions about SUDs were asked of 12,182 regular alcohol users and 1,788 cannabis users.

Measurements: Each survey used the World Mental Health Survey Initiative version of the WHO Composite International Diagnostic Interview Version 3.0 (WMH-CIDI).

Findings: Among regular alcohol users, prevalence (95\% confidence interval) of lifetime ICD-11 alcohol harmful use and dependence were $21.6 \%$ (20.5\%-22.6\%) and 7.0\% (6.4\%-7.7\%), respectively. Among cannabis users, $9.3 \%(7.4 \%-11.1 \%)$ met criteria for ICD-11 harmful use and 3.2\% (2.3\%-4.0\%) for dependence. For both substances, all comparisons of ICD-11 with ICD-10 and DSM-IV showed excellent concordance (all $\kappa \geq 0.90$ ). Concordance between ICD-11 and DSM-5 ranged from good (for SUD, and comparisons of dependence and severe SUD) to poor (for comparisons of harmful use and mild SUD). Very low endorsement rates were observed for new ICD-11 feature for harmful use ('harm to others'). Minimal variation in clinical features was observed across diagnostic systems. 
Conclusions: The World Health Organization's proposed International Classification of Diseases, 11th Edition (ICD-11) classifications for substance use disorder diagnoses are highly consistent with the ICD $10^{\text {th }}$ Edition and the Diagnostic and Statistical Manual of Mental Disorders, $4^{\text {th }}$ Edition (DSM-IV). Concordance between ICD-11 and the DSM $5^{\text {th }}$ Edition (DSM-5) varies, largely due to low levels of agreement for the ICD harmful use and DSM-5 mild use disorder. Diagnostic validity of self-reported "harm to others" is questionable.

Funding: World Health Organization, Australian National Health and Medical Research Council 


\section{Introduction}

The diagnostic assessment of people with substance use disorders (SUDs) may produce varying results depending on the classification, definition and diagnostic guidelines used; an inherent problem of many mental health disorders given the lack of objective biological measures. The issues facing investigations of diagnostic validity, and strategies to investigate validity, have been outlined by eminent clinicians and researchers (e.g. ${ }^{1-6}$ ). They argued that to establish validity of a syndrome, one needed: a description of the syndrome (including the profile of symptoms as well as characteristics and risk factors for the syndrome); distinction from other disorders; prognostic value of the description; family studies showing evidence of heritability; and treatment response $^{1-3}$. Although people have debated whether these things demonstrate validity as opposed to clinical utility $^{2,5}$, the ongoing influence of definitions of SUDs arises in large part because of clinical utility, which is given a particular importance in the process of developing the International Classification of Diseases, 11th Edition (ICD-11) for mental and behavioural disorders, including SUDs ${ }^{7}$.

The nomenclature of substance-related problems has evolved over time ${ }^{8}$. In 1964, the World Health Organization (WHO) Expert Committee on Addiction-Producing Drugs proposed the term "drug dependence" to replace the term "addiction" and "drug habituation", which have strongly been associated with opioids". The operationalisation of a substance "dependence syndrome" was influenced by Edwards and colleagues' work on alcohol dependence ${ }^{10}$, whereby it was suggested that alcohol dependence could be conceptualised as a cluster of symptoms occurring in heavy drinkers that were distinguishable from alcohol-related problems ${ }^{11}$ (i.e. separate from "harmful use" or "abuse"), since extended to cannabis and other drugs. The category of "substance abuse" or "harmful use" was developed to classify persons who experienced clinically significant problems associated with their substance use that resulted in social or health harms but were not using the substance in a compulsive manner.

The International Classification of Diseases (ICD) and the Diagnostic and Statistical Manual of Mental Disorders (DSM) are the most widely used psychiatric classification systems for SUDs. The WHO's ICD $10^{\text {th }}$ Edition (ICD-10) distinguishes between harmful use, defined as a pattern of substance use that is causing damage to physical or mental health, and dependence, a cluster of symptoms that typically include craving, difficulties in controlling use, preoccupation with the substance, persisting use despite recurrent adverse consequences, tolerance and withdrawal ${ }^{12}$. The first "beta" version of ICD-11 draft descriptions was released in July $2014^{13}$ with subsequent updated versions and release in October 2016 of the International Classification of Diseases for Morbidity and Mortality Statistics for Member States comments, and the release of ICD-11 is expected in 2018.

The draft proposal for ICD-11 substance dependence retains the concept of a "dependence syndrome" but proposes that the criteria (or "essential features") of the disorder be reduced from six to three, with an individual 
needing to meet at least two criteria for substance dependence. The extent to which the compounded criteria within these new features co-occur, potentially rendering some essentially redundant, has not been investigated, but is an important question.

The draft proposal for ICD-11 "harmful use" requires clinically significant harm to physical or mental health of an individual due to a pattern of use of a psychoactive substance that is typically evident over a period of at least 12 months. The diagnostic concept of "harmful use" in the draft ICD-11 introduces a "harm to others" criterion as substance-induced behavior leading to clinically significant harm to the health of others. The term "harmful use" in the draft ICD-11 was later replaced with the term "harmful pattern of substance use".

For international research, it is essential to ensure the consistency of within-subject diagnostic findings across countries, languages and cultures. Similarly, it is important to understand if the clinical and demographic profile of cases varies across diagnostic systems. To date, agreement analyses between different diagnostic systems for drugs and alcohol have largely been based in high-income countries ${ }^{14-20}$ and in some cases, clinical samples rather than general population samples e. $\mathrm{g}^{15,20}$. There exists two cross-national nosological studies of alcohol or cannabis use disorders ${ }^{21,22}$, however these were conducted before efforts to revise the ICD-10 into ICD-11 had begun. This study, undertaken in the framework of WHO-led activities on testing of ICD-11, is therefore, to our knowledge, the first cross-national study to examine the proposed ICD-11 classification of people with alcohol and cannabis use disorders in the general population compared with other ICD and DSM definitions.

Using data from ten surveys collected through the WHO's World Mental Health Survey (WMHS) Initiative, we aimed to:

1. Evaluate concordance of the proposed ICD-11 definitions and diagnostic guidelines of harmful use and dependence with ICD-10, DSM-IV and DSM-5 diagnoses;

2. Investigate what impact the addition of the concept of "harm to others" has on the prevalence of ICD-11 harmful use, and its concordance with ICD-10 harmful use;

3. Examine the impact of condensing six ICD-10 dependence criteria into three essential diagnostic features in ICD-11;

4. Summarise demographic and clinical correlates across all classification system disorder groupings. 


\section{Methods}

\section{Survey Sample}

The WMHS are a series of epidemiological surveys initiated by the WHO designed to collect and provide information on the prevalence, correlates, burden and treatment of mental disorders in countries throughout the world. The current study uses data from ten surveys (see Table 1); one survey was carried out in a country classified by the World Bank at time of data collection as lower-middle income (a national survey in Iraq), three in countries classified as upper-middle income (a national survey in Romania, a regional survey in São Paulo, Brazil and a city survey in Medellin, Colombia) and six in countries classified as high income (national surveys in Argentina, Australia, Northern Ireland, Portugal and Poland, and a regional survey in Murcia, Spain). Most surveys were based on a multi-stage clustered area probability sampling design of adult (aged 18 and over) household residents. The average response rate across surveys was 65.6\% ranging from 50.4\% (Poland) to $97.2 \%$ (Medellin). The total sample size of participating adults from these surveys was 48,268.

\section{Table 1 about here}

All interviews were carried out face-to-face with respondents in their homes by trained lay interviewers. Verbal or written consent was obtained prior to study participation. All procedures were reviewed and monitored by local review boards. Each survey used the WMH Survey Initiative version of the WHO Composite International Diagnostic Interview Version 3.0 (WMH-CIDI), a validated fully-structured diagnostic instrument. ${ }^{23}$ The instrument has been translated into a number of languages using standardised translation procedures ${ }^{24,25}$. The instrument has been extensively tested and SUD diagnoses have previously been shown to be in fair to substantial agreement to diagnoses obtained through clinician-administered interviews. ${ }^{26}$ A brief overview of the WMH-CIDI structure is provided in the appendix. As Portugal did not assess drug use disorders (DUDs), their data was used only in the analysis of alcohol use disorders (AUDs). Person-level analysis weights incorporated probability of selection, non-response and post-stratification factors, therefore providing representative data on the target adult general population. More detailed descriptions of the survey methods, instrument development and weighting procedures are described elsewhere. ${ }^{27}$

\section{Substance Use Disorder Diagnoses}

The WMH-CIDI substance use modules compile symptomatic information relating to lifetime alcohol and drug use disorders diagnoses. The instrument was developed to assess DSM-IV and ICD-10 SUDs derived with diagnostic algorithms ${ }^{12,28}$. Similar algorithms corresponding to the respective diagnostic formulations were applied to symptom information for the complete derivation of DSM-5 and ICD-11 diagnoses. The new DSM-5 criterion representing craving was captured through the same WMH-CIDI question originally defined for use in 
the ICD-10 dependence algorithm. WMH-CIDI questions, represented by key phrases (KP), were mapped to the three diagnostic criteria for ICD-11 dependence ${ }^{29}$ as follows:

- 'Impaired control over substance use' is defined in terms of the onset (KP: used it even though promised yourself you wouldn't), level (KP: used more frequently than intended), circumstances or termination of use (KP: tried to stop and was not able to) which may be accompanied by a subjective sensation of urge or craving to use the substance (KP: not able to resist it).

- 'Substance use becomes an increasing priority in life' such that its use takes precedence over other interests or enjoyments, daily activities, responsibilities, or health or personal care (KP: reduced important activities). Substance use takes an increasingly central role in the person's life and relegates other areas of life to the periphery (KP: had little time for anything else). Substance use often continues despite the occurrence of problems (continued use despite it causing, KP1: physical or emotional problems; or KP2: problems with family, friends or others).

- 'Physiological features' (indicative of neuroadaptation to the substance) as manifested by tolerance (KP: needed to use more to get an effect), withdrawal symptoms following cessation or reduction in use of that substance (KP: stopped, cut-down or went without using, and experienced symptoms like fatigue, headaches, diarrhea, the shakes or emotional problems), or repeated use of the substance to prevent or alleviate withdrawal symptoms (KP: used to keep from experiencing these symptoms). Withdrawal symptoms must be characteristic for the withdrawal syndrome for that substance and must not simply reflect a hangover effect.

Harmful pattern of use is defined as a pattern of substance use causing damage to a person's physical or mental health, but which has not yet resulted in consistently impaired control over consumption, physiological features or persistence in use despite harm. Such patterns of use may have also resulted in behaviour leading to harm to the health of others. Harm may be due to behaviour related to intoxication, direct or secondary toxic effects on body organs and systems, or a harmful mode of administration ${ }^{29}$.

To facilitate the assessment of ICD-11 harmful use, a series of items used in the ICD-10 harmful use algorithm, and which also align with similar ICD-11 harmful use features, were identified. These items represent behaviours likely to eventuate in damage to a person's physical (KP: jeopardised your safety because you sometimes drank in situations where you could get hurt) or mental health (KP1: resulted in problems with the police, or KP2: interfered frequently with your work or responsibilities at school, on a job, or at home). The additional feature 'harm to the health of others' in ICD-11 harmful use was not assessed so harm to family (KP: family been hurt by your substance use) was used as a proxy measure. As Poland, Portugal and Argentina surveys did not collect information relating to whether a person's family had been hurt by their substance use, ICD-11 harmful use diagnoses for these three surveys do not account for this criterion. Regardless, as endorsement rates were very low in surveys that did assess this criterion, and because the complete ICD-11 
dependence could be derived, we retain these three surveys in our comparisons under the proviso that their ICD11 harmful use rates are conservative estimates.

\section{Statistical Analysis}

All analyses were carried out in SAS 9.4, included person weights and adjusted for stratification and clustering. AUD analyses are restricted to respondents who, in the year they drank most, consumed alcohol at least three times per week or, if less often, consumed three or more standard alcoholic drinks per drinking day (here on defined as 'regular users'). Some surveys assessed DUDs broadly for all drugs while others assessed DUDs for each specific drug. As the current study focuses on cannabis-specific use disorders, the cannabis use disorder (CUD) analyses are restricted to those who had only ever used cannabis in their lifetime. This was to ensure that reported DUD symptoms were entirely attributable to cannabis use. In Australia, Iraq and Brazil, respondents had to have used cannabis at least five times in their lifetime to be asked DUD questions and, for this reason, CUD analyses in those surveys are further restricted to the subset that met that threshold.

An error in a subset of questionnaires (Australia, Northern Ireland, Medellin and Murcia) resulted in 270 cannabis users unintentionally skipping over the dependence item "cut down". We imputed data for these people (see Appendix).

We report prevalence (and standard errors) at the disorder level for all diagnoses. To investigate the underlying structure of the diagnoses, we also report disaggregated ICD-10 and ICD-11 symptom-level prevalence. Individual-level concordance across diagnoses was evaluated using Cohen's $\kappa \cdot{ }^{30}$ Descriptors of the degree of agreement are modelled on guidelines reported by Fleiss; ${ }^{31} \kappa$ estimates less than 0.40 are interpreted as poor, between 0.40 and 0.64 as fair, 0.65 to 0.75 as good and excellent for $\kappa$ greater than 0.75 .

For crosstabulations of DSM-5 and ICD-10 diagnostic categories, we applied the cross-walk coding information provided in the DSM- $5^{28}$. Specifically, both severe and moderate DSM-5 SUD diagnoses are grouped for comparisons with ICD-10 dependence, while mild DSM-5 diagnosis is compared to ICD-10 harmful use. We also compared ICD-10 dependence with all DSM-5 diagnoses, and with severe DSM-5 disorder alone, but did not investigate comparisons with moderate DSM-5 disorder alone. With the high level of criteria overlap, those with a severe DSM-5 diagnosis are highly likely to meet criteria for ICD-10 dependence. Compounded with the fact that the DSM-5 dimensional approach means that all those with a severe DSM-5 diagnosis also meet the threshold for moderate DSM-5 diagnosis, comparisons of moderate DSM-5 diagnosis alone (i.e. excluding severe cases) with ICD-10 dependence would be inappropriate. The same cross-walk framework was used for crosstabulations of DSM-5 with the proposed ICD-11 system. 


\section{Results}

In this paper we focus on diagnostic guidelines and criteria for SUDs across classifications among lifetime regular alcohol users or lifetime cannabis users. Table 2 shows the prevalence of people within each substance group who endorsed each diagnostic criterion under the ICD classifications, and who met diagnostic criteria under each of the four classification systems considered.

\section{Disorder Prevalence}

The combined sample of all surveys included 12,182 lifetime regular alcohol users (Table 2). Among those users, the pooled prevalence of lifetime ICD-11 AUDs was $28.4 \%$ overall but varied across countries, ranging from $16.4 \%$ in Murcia to $45.7 \%$ in Iraq (see Appendix Table A1 for country-specific alcohol prevalence). With pooled AUD rates of $31.0 \%$ for ICD-10, 30.1\% for DSM-IV and $27.4 \%$ for DSM-5, AUD prevalence was similar across all classification systems. Lifetime ICD-11 dependence and harmful use rates among lifetime regular alcohol users were $7.0 \%$ and $21.6 \%$, respectively.

Among the 1,788 cannabis users in the pooled sample who were asked about CUDs, lifetime ICD-11 CUD prevalence was $12.2 \%$ and ranged from no CUDs in Iraq and Romania to $22.9 \%$ in Sao Paulo, Brazil (see Appendix Table A2 for country-specific cannabis prevalence). These CUDs rates were similar compared to the other classification systems considered; pooled CUD prevalence was $13.8 \%$ for ICD-10, 13\% for DSM-IV and $11.5 \%$ for DSM-5. Lifetime ICD-11 dependence and harmful use rates among cannabis users were $3.2 \%$ and $9.3 \%$, respectively.

\section{Table 2 about here}

\section{Symptom Prevalence in ICD-11 disorder definitions}

By far, the most commonly endorsed ICD-11 dependence feature was 'impaired control' with $32.7 \%$ of alcohol users and $12.3 \%$ of cannabis users having experienced related symptoms. For both substances, impaired control' was most often present due to difficulties in controlling use attributable to using larger amounts/more frequently than intended or being unable to cut-down. 'Centrality of drug use' was the second most common symptom (endorsed by $17.8 \%$ of alcohol users and $8 \%$ of cannabis users) and explained in large part by the indication of continued use despite recurrent social or interpersonal problems (alcohol), or recurrent physical or psychological problems (cannabis). The least endorsed ICD-11 symptom of substance dependence for both alcohol and cannabis was 'physiological signs', though the difference in prevalence between this symptom and 'centrality of drug use' was small for cannabis ( $7.6 \%$ versus $8.0 \%)$ in comparison to alcohol $(13.5 \%$ versus $17.8 \%)$. 
Within the ICD-11 harmful use structure, the most frequently endorsed symptom at the survey level was either 'recurrent use resulting in failure to fulfil major obligations' or 'recurrent use in hazardous situations' for both substances. Reporting that 'one's family [had] been hurt by one's use' was the least endorsed ICD-11 harmful use symptom across all surveys with only $1.8 \%$ of alcohol users and $0.3 \%$ of cannabis users from the pooled survey samples endorsing this symptom. When excluding 'harm to others' from the ICD-11 harmful use algorithm, no change was observed in any country-specific cannabis harmful use rates. Similarly, exclusion of this criterion from the diagnosis of alcohol harmful use decreased the overall prevalence at most by $0.4 \%$.

Crosstabulations displaying the co-occurrence of items within each of the three ICD-11 symptoms, broken down by dependence, are presented for both substances in the Appendix Tables A3-A6. Results from two parameter logistic item response models for ICD-10 and ICD-11 among regular alcohol users and cannabis users are provided in Appendix Table A7.

As 'harm to others' provided very little additional information to harmful use diagnoses, all ICD-11 diagnoses from here onwards report harmful use without harm to others (WHTO) to allow for data from Poland, Portugal and Argentina to be incorporated. Sensitivity analyses were conducted investigating the concordance and prevalence estimates excluding these three countries and using the complete ICD-11 definition including harm to others, and the findings were consistent.

\section{Concordance between classification systems}

Concordance was excellent between all comparisons of ICD-11 (WHTO), DSM-IV and ICD-10 AUDs (Table 3). Agreement was also excellent for all comparisons between ICD-11 harmful use (WHTO), DSM-IV abuse and ICD-10 harmful use (Table 4), and between ICD-11, DSM-IV and ICD-10 dependence (Table 5). Concordance of ICD-11 and DSM-5 definitions was noticeably lower; agreement was good for ICD-11 and DSM-5 AUDs, fair for ICD-11 dependence and DSM-5 moderate/severe AUD, and poor for ICD-11 harmful use and DSM-5 mild AUD. Findings were similar comparing DSM-5 with DSM-IV and ICD-10 AUDs.

Concordance between DSM-IV, ICD-10 and ICD-11 CUDs was excellent, as were all comparisons of cannabis abuse/harmful use and cannabis dependence. Agreement between DSM-5 and ICD-11 for cannabis diagnoses was at most good for CUD, good between dependence and moderate/severe CUD, and poor for the comparison between harmful use and mild CUD. DSM-5 CUDs achieved the greatest agreement with both DSM-IV and ICD-10 cannabis dependence using a cut-off of severe, though this agreement was no more than good.

Among those with a DSM-5 diagnosis, the proportion of respondents with no diagnosis under other diagnostic systems ranged from $15.5 \%$ (ICD-10) to $20.9 \%$ (ICD-11) for AUDs and 24.3\% (ICD-10) to 29.1\% (ICD-11) for CUDs (Table 3). It is noteworthy, however, that overall there were less cases identified in the DSM-5 system than the other definitions. Table 6 shows the crosstabulations of all ICD-11 diagnostic categories with ICD-10 
and DSM-5 diagnostic categories. Figure 1 shows the overlap of ICD-10, ICD-11 and DSM-5 definitions of alcohol and cannabis dependence (moderate/severe SUD for DSM-5). Both clearly demonstrate the almost complete agreement of the two ICD definitions, and much poorer overlap for DSM-5 due to the different group this definition identified.

\section{Table 3, 4, 5 and 6 about here}

\section{Figure 1 about here}

\section{Associations with other clinical and demographic variables}

Comparisons of clinical and demographic correlates between classification system subgroups showed minimal variation for AUD and CUD definitions (Table 7). Medians of age of onset, age of onset of first symptom and age at interview were largely consistent across all classification systems, use disorder/dependence groupings and substances. Looking within classification systems, past-year symptoms, family history of problematic use, lifetime hospital treatment, past year treatment and unemployment tended to be higher among dependence cases compared to the pooled AUD sample of the same classification system. Lifetime diagnoses of generalised anxiety disorder, affective disorders and cannabis dependence were also more common among alcohol dependence cases. Conversely, dependence cases had lower high school completion rates for alcohol and lower marriage rates compared to the pooled groups.

Table 7 about here 


\section{Discussion}

We used cross-national community epidemiological survey data of lifetime regular alcohol users and cannabis users to investigate the diagnostic guidelines for proposed ICD-11 AUD and CUD diagnoses and their concordance with other classification systems (DSM-IV, DSM-5 and ICD-10). For both substances, all comparisons of ICD-11 with ICD-10 and DSM-IV showed excellent concordance. As found in previous works, DSM-5's agreement with ICD-11 was more variable ${ }^{15}$. DSM-5 and ICD-11 concordance was good (cannabis) to fair (alcohol) for comparisons of dependence and moderate/severe CUDs or AUDs ${ }^{15}$, and poor between ICD-11 harmful use and DSM-5 mild SUD.

We found very low rates of endorsement of one question that is related to proposed new ICD-11 feature for harmful use, namely harm to others, as assessed in the CIDI. This may have been for several reasons. First, if a person caused harm to others through their substance use, they may be unwilling to report, or unaware of, the consequences it has had on those around them, an issue highlighted in previous research ${ }^{32}$. As operationalised in the CIDI interview, this feature was found to add very little information to the harmful use diagnoses. Endorsement rates were the lowest of all ICD criteria and its exclusion from the diagnostic algorithm had little to no impact on the overall harmful use prevalence rate. The limited capacity of self-assessments to evoke a reliable response might indicate it is more suitable to ask about this feature where the accounts of family or friends can be considered, such as in a clinical setting.

Second, it is also possible that the way in which the question was worded meant that the CIDI did not capture the criterion adequately. In fact, in the draft ICD-11 it is rather an expansion of the boundaries of "harm to health" by including harm to health of others than an additional diagnostic criterion and not limited to family members. The criterion specified by WHO describes harm to others as any kind of physical or mental health harm that is attributable to substance-induced behavior, which may not have been adequately captured in the CIDI question "How much has your family been hurt by your [substance use]?". Third, it is possible that harming one's family is more associated with more severe disorder, but more severe disorder is associated with having fewer close relationships or less regular family interactions. Future research might examine both the validity of the expanded concept of "harm" due to substance use in the draft ICD-11 and how to address this concept in diagnostic and screening instruments.

It is important to note DSM-5's atheoretical approach, and de-emphasis of symptom constellations or subtypes. ICD-11 has taken the opposite approach and attempts to aggregate clinical signs into the fewer interrelated essential features. Comparisons of agreement between levels of DSM-5 severity and either ICD-10, ICD-11, or DSM-IV dependence or harmful use could be argued to be somewhat problematic, unless it is assumed that harmful use is necessarily less severe than dependence (which other research findings do not consensually support $^{33-37}$ ). DSM-5's implicit goals are to identify cases and to assign severity based on symptom count. To 
that end, when we compared the agreement of DSM-5 and the other systems in identifying AUDs and CUDs overall, agreement was good. However, it is important to note that up to $29.1 \%$ of people identified as cases in DSM-5 were not identified as cases in the other three classification systems; and up to $37.0 \%$ of cases of use disorder in the other classification systems were not classified as cases under DSM-5. Though the former may partially be explained by DSM-5's ability to account for "diagnostic orphans" ${ }^{38}$, these findings are not restricted to the lowest levels of DSM severity. It would be of value to investigate these inconsistent cases in more depth to determine the implications of excluding such a high proportion of people defined as cases in other systems and including in the DSM-5 definition such a high proportion of cases that are not defined as cases in the other systems. It would also be valuable to reconsider the thresholds for 'mild', 'moderate' and 'severe' use disorders empirically to allow these to fall at symptom counts more consistent with the prior DSM incarnation and the ICD systems.

As noted earlier, a major challenge to nosology in the drug and alcohol field concerns the lack of an objectively determined gold standard method of defining SUDs. To that end, when different classification systems differ in classifying individuals, in the characteristics of those individuals and even in the rate of occurrence of a disorder, it is difficult to know which definition has achieved a more "accurate" encapsulation of the concepts that are intended to be captured. In the case of our study, to the extent that there was less strong agreement between ICD-11 and DSM-5, even when defined as moderate/severe, DSM-5 was measuring a slightly different construct to the other classification systems. Aside from introducing uncertainty around measurement and issues of implementation e.g.in clinical settings, it is difficult to know how this can easily be resolved without broad consensus on an approach to definition across the varied expert committees in this area. Future studies might examine other aspects of proposed strategies to examine diagnostic validity in psychiatry, including longitudinal course of disorder, response to treatment and extent of heritability.

This study, and previous works, have shown that specific diagnostic criteria tend to indicate varying levels of disorder severity (see Item Response Theory (IRT) Analysis Results in Appendix Table A7) ${ }^{39-41}$. With the simplification of the ICD-11 dependence structure, it stands to reason that meeting dependence criteria in population surveys will typically be determined by endorsement of the less severe criteria, as these will be more commonly reported than the more severe criteria ${ }^{15}$; the same may not be the case in the clinical setting, where more severe cases may predominate. The two most frequently endorsed dependence symptoms among alcohol users in the current study, 'difficulty in controlling use' and 'continued use despite problems', fall under two separate ICD-11 dependence features; endorsing both would satisfy criteria for ICD-11 dependence. The restructuring of ICD dependence symptoms appeared to increase identification of alcohol dependence cases and had the converse effect on cases of harmful use, resulting in a drop of the overall rate of use disorders. The implications of this are unclear, but it does raise the question as to whether the weight of different symptoms and severity of features should be taken in to account in the assigning of diagnoses. 
As previously mentioned, one of the strengths of this paper was that it used data from countries with varied cultural and income levels, permitting some examination of potential differences in classification across countries. Although there were more cases from high income countries, our IRT analyses did suggest that people responded to the ICD-11 items differently across high versus low income countries (Appendix Table A7). Further studies of this in varied countries may shed light on the importance of these differences.

\section{Limitations}

One limitation is the potential biases that may be introduced by the reliance on self-report data. However, we used a well-validated structured diagnostic interview to collect symptoms of SUD, though the CIDI instrument was developed before introduction of innovations in DSM-5 and ICD-11. Self-report of substance use behaviours is also reliable when confidentiality is assured and there are no disincentives for being honest ${ }^{42,43}$, as was the case in this study, though, as discussed above, it can be different regarding the impact of substanceinduced behaviours on health of others.

Three surveys (Poland, Portugal and Argentina) did not assess the CIDI item "family been hurt by others" reflecting the inclusion of harm to health of others in the proposed diagnostic guidance for the "harmful use" in ICD-11 and thus harmful use rates from these surveys are conservative estimates. In terms of diagnostic concordance results, as previously mentioned, sensitivity analyses including only those surveys for which complete ICD-11 harmful use definitions and diagnostic guidelines could be assessed produced consistent results.

Although the WMH-CIDI was constructed to allow the evaluation of ICD-10 diagnoses, the features used in the algorithms for constructing ICD-10 harmful use do not directly map to the diagnosis definition. Rather, a series of situations or behaviours that may have (but didn't necessarily) eventuate in harm and which were directly attributable to substance use were used as proxy measures to capture the diagnostic features. Considering the large overlap between ICD editions, this extends also to evaluation of ICD-11 harmful use. Despite this potential issue, the use of these proxy measures appears to work sufficiently well in the current study, with comparisons of both ICD-10 and ICD-11 with DSM-IV in excellent agreement for both harmful use/abuse and, more broadly, SUDs.

Response rates of the surveys varied widely. Though post-stratification adjustments were conducted to control for differential response, there remains the possibility that survey participation may be related to the presence of a SUD in ways that were not corrected. With that in mind, and considering previous works that suggest household and community-based surveys produced underestimates of substance use problems ${ }^{44-46}$, prevalence estimates presented here are likely underestimates. 
A lack of representation from North America and most of Northern Europe is a noticeable absence. Some of the earliest WMHS were conducted in these regions, however, a skip error in an early version of the survey instrument meant all persons who did not meet criteria for abuse were not asked questions relating to dependence. As a result, we have no dependence criteria data for these cases. For this reason, countries with the skip error (which includes the United States and most European surveys) could not be included in the current study.

Finally, some of the surveys included in the current study were conducted years ago. Although policies, attitudes and rates of use of these substances may have changed since data collection, we have no reason to suspect this would impact concordance results between diagnostic systems.

\section{Conclusions}

The classification of SUDs has varied across versions and systems. While changes with each revision are mostly incremental, there is the need for ongoing review of these classifications to ensure consistency with previous editions and that improvements are in line with developing knowledge. ICD-11 aggregated essential features for alcohol and cannabis dependence as well as for AUDs and CUDs showed excellent concordance (kappa $\geq 0.9$ ) with ICD-10 and DSM-IV. However, the concordance of AUDs and CUDs between ICD-11 and DSM-5 varies from good to poor largely - but not exclusively - due to low levels of agreement for the ICD harmful substance use and mild SUD in DSM-5. Diagnostic validity of self-reported "harm to others" is questionable and requires further research. The increased number of cases of alcohol dependence identified in ICD-11 compared to ICD10 needs further exploration. It may be of use to have some consideration for revisiting DSM-5 thresholds, considering the data presented here. It is crucial that further testing of diagnostic guidelines of ICD-11 be conducted to determine their impact, and if varying definitions are better suited for different settings or research methods. 


\section{Acknowledgments}

This work was supported by an Australian National Health and Medical Research Council (NHMRC) project grant (no. 1081984) and the World Health Organization. LD is supported by an NHMRC Principal Research Fellowship.

The World Health Organization World Mental Health (WMHS) Survey Initiative is supported by the United States National Institute of Mental Health (NIMH; R01 MH070884), the John D. and Catherine T. MacArthur Foundation, the Pfizer Foundation, the United States Public Health Service (R13-MH066849, R01-MH069864, and R01 DA016558), the Fogarty International Center (FIRCA R03-TW006481), the Pan American Health Organization, Eli Lilly and Company, Ortho-McNeil Pharmaceutical Inc., GlaxoSmithKline, and Bristol-Myers Squibb. We thank the staff of the WMH Data Collection and Data Analysis Coordination Centres for assistance with instrumentation, fieldwork, and consultation on data analysis. The views and opinions expressed in this report are those of the authors and should not be construed to represent the views of the World Health Organization, other sponsoring organizations, agencies, or governments, and do not necessarily represent the views, official policy, or position of the US. Department of Health and Human Services or any of its affiliated institutions or agencies.

The 2007 Australian National Survey of Mental Health and Wellbeing is funded by the Australian Government Department of Health and Ageing. The Argentina survey -- Estudio Argentino de Epidemiología en Salud Mental (EASM) -- was supported by a grant from the Argentinian Ministry of Health (Ministerio de Salud de la Nación). The São Paulo Megacity Mental Health Survey is supported by the State of São Paulo Research Foundation (FAPESP) Thematic Project Grant 03/00204-3. The Mental Health Study Medellín - Colombia was carried out and supported jointly by the Center for Excellence on Research in Mental Health (CES University) and the Secretary of Health of Medellín. Implementation of the Iraq Mental Health Survey (IMHS) and data entry were carried out by the staff of the Iraqi MOH and MOP with direct support from the Iraqi IMHS team with funding from both the Japanese and European Funds through United Nations Development Group Iraq Trust Fund (UNDG ITF). The Northern Ireland Study of Mental Health was funded by the Health \& Social Care Research \& Development Division of the Public Health Agency. The Polish project Epidemiology of Mental Health and Access to Care -EZOP Project (PL 0256) was supported by Iceland, Liechtenstein and Norway through funding from the EEA Financial Mechanism and the Norwegian Financial Mechanism. EZOP project was co-financed by the Polish Ministry of Health. The Portuguese Mental Health Study was carried out by the Department of Mental Health, Faculty of Medical Sciences, NOVA University of Lisbon, with collaboration of the Portuguese Catholic University, and was funded by Champalimaud Foundation, Gulbenkian Foundation, Foundation for Science and Technology (FCT) and Ministry of Health. The Romania WMH study projects "Policies in Mental Health Area" and "National Study regarding Mental Health and Services Use" were carried 
out by National School of Public Health \& Health Services Management (former National Institute for Research \& Development in Health), with technical support of Metro Media Transilvania, the National Institute of Statistics-National Centre for Training in Statistics, SC, Cheyenne Services SRL, Statistics Netherlands and were funded by Ministry of Public Health (former Ministry of Health) with supplemental support of Eli Lilly Romania SRL. The Psychiatric Enquiry to General Population in Southeast Spain - Murcia (PEGASUS-Murcia) Project has been financed by the Regional Health Authorities of Murcia (Servicio Murciano de Salud and Consejería de Sanidad y Política Social) and Fundación para la Formación e Investigación Sanitarias (FFIS) of Murcia.

A complete list of all within-country and cross-national WMH publications can be found at http://www.hcp.med.harvard.edu/wmh/. 


\section{References}

1. Robins E, Guze S. Establishment of diagnostic validity in psychiatric illness:Its application to schizophrenia. American Journal of Psychiatry. 1970; 126: 983-7.

2. Robins L. Using Survey Results to Improve the Validity of the Standard Psychiatric Nomenclature. Archives of General Psychiatry. 2004; 61: 1188-94.

3. Kendell RE. Clinical validity. Psychological Medicine. 1989; 19(1): 45-55.

4. Kendell RE. Clinical validity. In: Robins LN, Barrett JE, eds. The Validity of Psychiatric Diagnosis. New York: Raven Press; 1989: 305-21.

5. Kendell R, Jablensky A. Distinguishing Between the Validity and Utility of Psychiatric Diagnoses. American Journal of Psychiatry. 2003; 160(1): 4-12.

6. Kendler KS. The nosologic validity of paranoia (simple delusional disorder). A review. Arch Gen Psychiatry. 1980; 37(6): 699-706.

7. First MB, Reed GM, Hyman SE, Saxena S. The development of the ICD-11 clinical descriptions and diagnostic guidelines for mental and behavioural disorders. World Psychiatry. 2015; 14(1): 8290.

8. Edwards G. "The evil genius of the habit": DSM-5 seen in historical context. Joural of Studies on Alcohol and Drugs. 2012; 73(4): 699-701.

9. World Health Organization. WHO Expert Committee on Addiction-Producing Drugs [meeting held in Geneva from 25 to 30 November 1963]: thirteenth report. 1964.

10. Edwards G, Gross M. Alcohol dependence: provisional description of a clinical syndrome. British Medical Journal. 1976; 1: 1058-61.

11. Edwards G, Gross M, Keller M, Moser J, Room R. Alcohol-related disabilities. Geneva: World Health Organization, 1977.

12. World Health Organization. The ICD-10 Classification of Mental and Behavioural Disorders Diagnostic Criteria for Research. Geneva: World Health Organization; 1993.

13. World Health Organization. ICD-11 Beta Draft. 2014. https://icd.who.int/browse11/l-m/en (accessed 20th February 2014).

14. Lago L, Bruno R, Degenhardt L. Concordance of ICD-11 and DSM-5 definitions of alcohol and cannabis use disorders: a population survey. The Lancet Psychiatry. 2016; 3(7): 673-84.

15. Chung T, Cornelius J, Clark D, Martin C. Greater Prevalence of Proposed ICD-11 Alcohol and Cannabis Dependence Compared to ICD-10, DSM-IV, and DSM-5 in Treated Adolescents. Alcoholism: Clinical and Experimental Research. 2017; 41(9): 1584-92.

16. Hoffmann NG, Kopak AM. How Well Do the DSM-5 Alcohol Use Disorder Designations Map to the ICD-10 Disorders? Alcoholism: Clinical and Experimental Research. 2015; 39(4): 697-701.

17. Lundin A, Hallgren M, Forsman M, Forsell Y. Comparison of DSM-5 classifications of alcohol use disorders with those of DSM-IV, DSM-III-R, and ICD-10 in a general population sample in Sweden. Journal of studies on alcohol and drugs. 2015; 76(5): 773-80.

18. Andrews G, Slade T. Depression, dysthymia and substance use disorders: sources of dissonance between ICD-10 and DSM-IV. International Journal of Methods in Psychiatric Research. 1998; 7(2): 116-20.

19. Horton J, Compton W, Cottler LB. Reliability of substance use disorder diagnoses among African-Americans and Caucasians. Drug \& Alcohol Dependence. 2000; 57(3): 203-9. 
20. Degenhardt L, Bruno R, Lintzeris N, et al. DSM and ICD definitions of pharmaceutical opioid dependence in people treated with opioids for chronic pain: Findings from the Pain and Opioids IN Treatment (POINT) study. The Lancet Psychiatry. 2015; 2(4): 314-22.

21. Slade T, Chiu WT, Glantz $M$, et al. A Cross-National Examination of Differences in Classification of Lifetime Alcohol Use Disorder Between DSM-IV and DSM-5: Findings from the World Mental Health Survey. Alcoholism: Clinical and Experimental Research. 2016; 40(8): 1728-36.

22. Hasin D, Grant BF, Cottler L, et al. Nosological comparisons of alcohol and drug diagnoses: a multisite, multi-instrument international study. Drug and Alcohol Dependence. 1997; 47(3): 217-26.

23. Kessler RC, Üstün TB. The World Mental Health (WMH) Survey Initiative version of the World Health Organization (WHO) Composite International Diagnostic Interview (CIDI). International Journal of Methods in Psychiatric Research. 2004; 13(2): 93-121.

24. Harkness J, Pennell B, Villar A, Gebler N, Aguilar-Gaxiola S, Bilgen I. Translation Procedures and Translation Assessment in the World Mental Health Survey Initiative. In: Kessler RC, Üstün TB, eds. The WHO World Mental Health Surveys: Global Perspectives on the Epidemiology of Mental Disorders. New York: Cambridge University Press; 2008: 91-113.

25. Mohler P, Dorer B, de Jong J, Hu M. Translation: Overview. Guidelines for Best

Practice in Cross-Cultural Surveys. Ann Arbor, MI: Survey Research Center, Institute for Social Research, University of Michigan; 2016: p. 233-85.

26. Haro JM, Arbabzadeh-Bouchez S, Brugha TS, et al. Concordance of the Composite International Diagnostic Interview Version 3.0 (CIDI 3.0) with standardized clinical assessments in the WHO World Mental Health Surveys. International Journal of Methods in Psychiatric Research. 2006; 15(4): 167-80.

27. Kessler RC, Üstün TB. The WHO Mental Health Surveys: global perspectives on the epidemiology of mental disorders. New York: Cambridge University Press; 2008.

28. American Psychiatric Association. Diagnostic and statistical manual of mental disorders : DSM-5: American Psychiatric Pub; 2013.

29. Saunders J, Peacock A, Degenhardt L. Alcohol use disorders in the draft ICD-11, and how they compare with DSM-5. Addiction Research. [under review].

30. Cohen J. A coefficient of agreement for nominal scales. Educational and Psychological Measurement. 1960; 20: 37-46.

31. Fleiss JL. Statistical methods for rates and proportions. 2nd ed. New York: Wiley; 1981.

32. Rossow I. How Well Do Survey Studies Capture Alcohol's Harm to Others? Substance Abuse: Research and Treatment. 2015; 9(Suppl 2): 99-106.

33. Langenbucher JW, Labouvie E, Martin CS, et al. An Application of Item Response Theory Analysis to Alcohol, Cannabis, and Cocaine Criteria in DSM-IV. Journal of abnormal psychology. 2004; 113(1): 72-80.

34. Kahler CW, Strong DR. A Rasch Model Analysis of DSM-IV Alcohol Abuse and Dependence Items in the National Epidemiological Survey on Alcohol and Related Conditions. Alcoholism: Clinical and Experimental Research. 2006; 30(7): 1165-75.

35. Muthén BO. Factor analysis of alcohol abuse and dependence symptom items in the 1988 National Health Interview survey. Addiction. 1995; 90(5): 637-45.

36. Proudfoot $\mathrm{H}$, Baillie AJ, Teesson $\mathrm{M}$. The structure of alcohol dependence in the community. Drug and Alcohol Dependence. 2006; 81(1): 21-6. 
37. Schuckit MA, Danko GP, Smith TL, Buckman KR. The Five-Year Predictive Validity of Each of the Seven DSM-IV Items for Alcohol Dependence Among Alcoholics. Alcoholism: Clinical and Experimental Research. 2006; 26(7): 980-7.

38. Hasin D, Paykin A. Dependence symptoms but no diagnosis: diagnostic 'orphans' in a community sample. Drug \& Alcohol Dependence. 1998; 50(1): 19-26.

39. Hartman CA, Gelhorn H, Crowley TJ, et al. An Item Response Theory Analysis of DSM-IV Cannabis Abuse and Dependence Criteria in Adolescents. Journal of the American Academy of Child and Adolescent Psychiatry. 2008; 47(2): 165-73.

40. Malone DT, Hill MN, Rubino T. Adolescent cannabis use and psychosis: epidemiology and neurodevelopmental models. British Journal of Pharmacology. 2010; 160(3): 511-22.

41. Martin CS, Chung T, Kirisci L, Langenbucher JW. Item response theory analysis of diagnostic criteria for alcohol and cannabis use disorders in adolescents: implications for DSM-V. Journal of abnormal psychology. 2006; 115(4): 807-14.

42. Chan D. So why ask me? Are self-report data really that bad? In: Lance CE, Vandenberg RJ, eds. Statistical and Methodological Myths and Urban Legends: Doctrine, verity and Fable in the Organizational and Social Sciences. New York: Taylor \& Francis; 2009: 309-36.

43. Darke S. Self-report among injecting drug users: a review. Drug and Alcohol Dependence. 1998; 51(3): 253-63.

44. UNODC. World Drug Report 2017. Vienna.: United Nations, 2017.

45. Morley KC, Teesson M, Reid SC, et al. Naltrexone versus acamprosate in the treatment of alcohol dependence: a multi-centre, randomized, double-blind, placebo-controlled trial. Addiction. 2006; 101(10): 1451-62.

46. Degenhardt L, Hall W. Extent of illicit drug use and dependence, and their contribution to the global burden of disease. Lancet. 2012; 379(9810): 55-70.

47. Hulsen T, de Vlieg J, Alkema W. BioVenn - a web application for the comparison and visualization of biological lists using area-proportional Venn diagrams. BMC Genomics. 2008; 9(1): 488. 
Table 1: WMH sample characteristics by World Bank income categories ${ }^{\mathrm{a}}$

\begin{tabular}{|c|c|c|c|c|c|c|c|}
\hline \multirow{2}{*}{ Country by income category } & \multirow{2}{*}{ Survey $^{b}$} & \multirow{2}{*}{ Sample characteristics $^{c}$} & \multirow{2}{*}{ Field dates } & \multirow{2}{*}{ Age range } & \multicolumn{2}{|c|}{ Sample size } & \multirow{2}{*}{ Response rate $^{e}$} \\
\hline & & & & & Part I & Part II & \\
\hline \multicolumn{8}{|c|}{ I. Low and lower middle income countries } \\
\hline Iraq & IMHS & Nationally representative. & $2006-7$ & $18-96$ & 4,332 & 4,332 & 95.2 \\
\hline \multicolumn{8}{|c|}{ II. Upper middle income countries } \\
\hline Brazil - São Paulo & São Paulo Megacity & São Paulo metropolitan area. & $2005-8$ & $18-93$ & 5,037 & 2,942 & 81.3 \\
\hline Colombia-Medellin & MMHHS & Medellin metropolitan area & 2011-12 & $19-65$ & 3,261 & 1,673 & 97.2 \\
\hline Romania & RMHS & Nationally representative. & $2005-6$ & $18-96$ & 2,357 & 2,357 & 70.9 \\
\hline \multicolumn{8}{|l|}{ III. High income countries } \\
\hline Argentina & AMHES & $\begin{array}{l}\text { Eight largest urban areas of the country (approximately } 50 \% \text { of the total } \\
\text { national population). }\end{array}$ & 2015 & $18-98$ & 3,927 & 2,116 & 77.3 \\
\hline Australia $^{\mathrm{f}}$ & NSMHWB & Nationally representative & 2007 & $18-85$ & 8,463 & 8,463 & 60.0 \\
\hline N. Ireland & NISHS & Nationally representative. & $2005-8$ & $18-97$ & 4,340 & 1,986 & 68.4 \\
\hline Poland & EZOP & Nationally representative & 2010-11 & $18-65$ & 10,081 & 4,000 & 50.4 \\
\hline Portugal & NMHS & Nationally representative. & $2008-9$ & $18-81$ & 3,849 & 2,060 & 57.3 \\
\hline Spain - Murcia & PEGASUS- Murcia & Murcia region. & 2010-12 & $18-96$ & 2,621 & 1,459 & 67.4 \\
\hline IV. Total & & & & & 48,268 & 31,388 & 65.6 \\
\hline
\end{tabular}

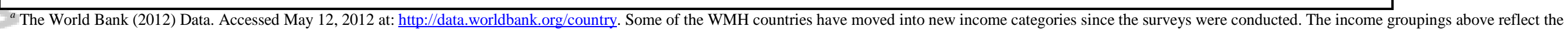
status of each country at the time of data collection. The current income category of each country is available at the preceding URL.

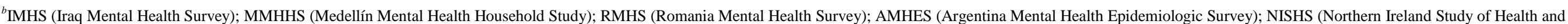

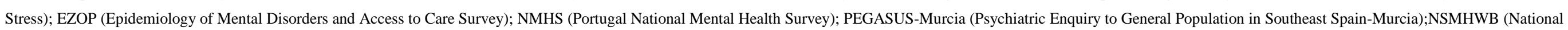
Survey of Mental Health and Wellbeing);

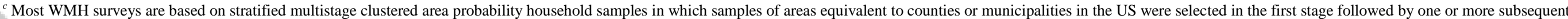

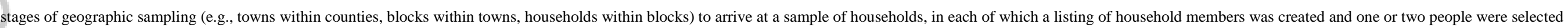

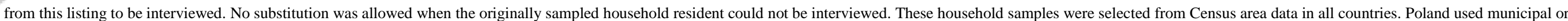
country resident registries to select participants without listing households. 7 of the 10 surveys are based on nationally representative household samples.

This article is protected by copyright. All rights reserved. 
${ }^{d}$ Argentina, Brazil, Colombia-Medellin, Iraq, Northern Ireland, Romania, and Spain-Murcia did not have an age restricted Part 2 sample. All other countries were age restricted to $\leq 44$

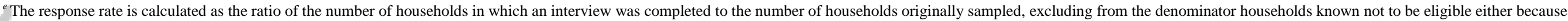
of being vacant at the time of initial contact or because the residents were unable to speak the designated languages of the survey. The weighted average response rate is 65.6 .

${ }^{f}$ For the purposes of cross-national comparisons we limit the sample to those $18+$ 
Table 2: Base rates of individual lifetime ICD-10 and ICD-11 symptom items, diagnostic categories, and use disorders for alcohol and cannabis among population of lifetime regular users of alcohol, and cannabis users

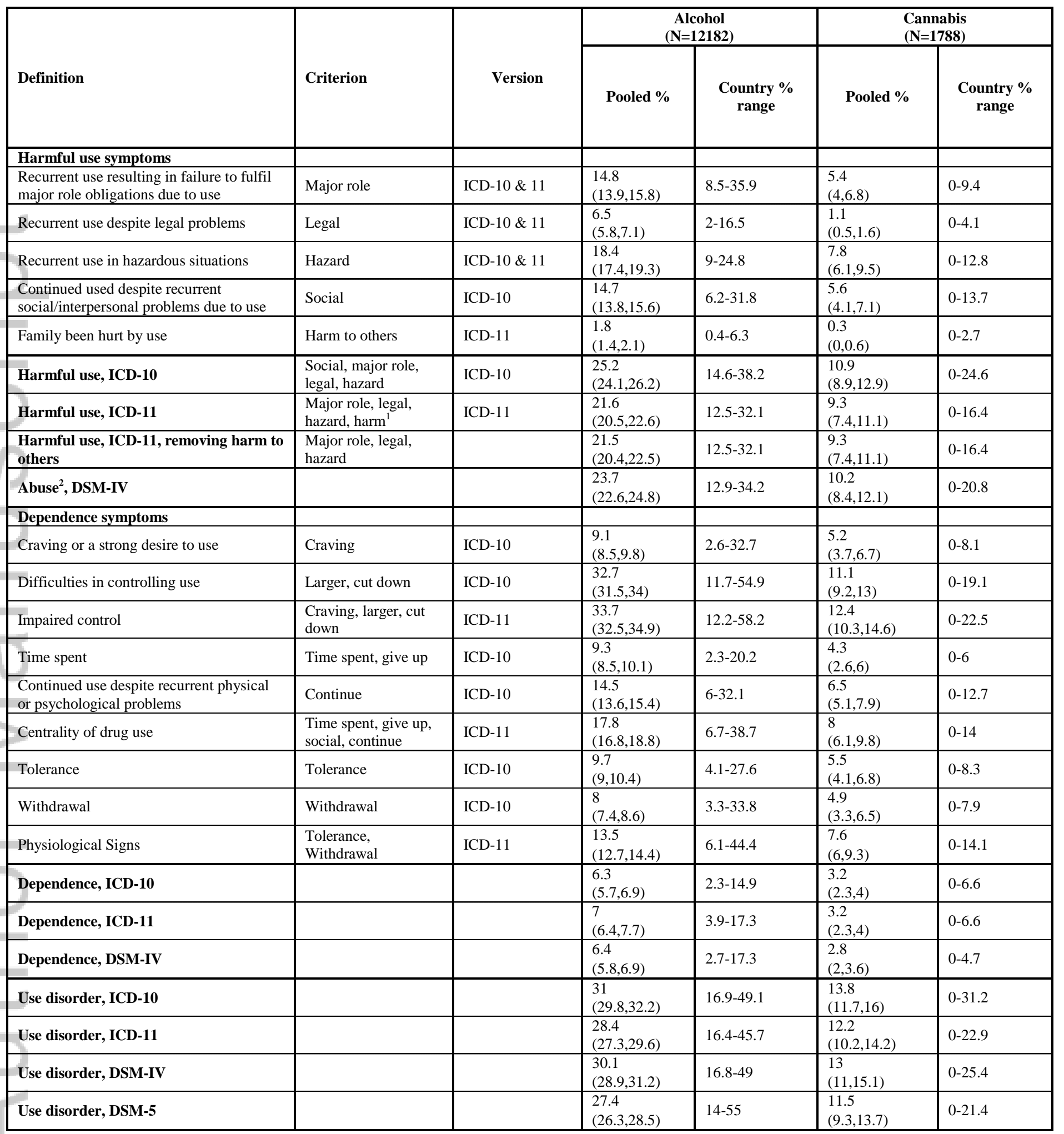

$\%$ - prevalence;

1. Criteria for 'Harm to others 'not collected in Portugal, Poland or Argentina.

2. Abuse without dependence 
Table 3: Crosstabulations and concordance between different definitions of alcohol and cannabis use disorders ${ }^{1}$

\begin{tabular}{|c|c|c|c|c|c|c|c|c|}
\hline \multirow[t]{2}{*}{ Among lifetime regular users of alcohol... } & \multicolumn{2}{|c|}{ DSM-IV use disorder } & \multicolumn{2}{|c|}{ DSM-5 use disorder } & \multicolumn{2}{|c|}{ ICD-10 use disorder } & \multicolumn{2}{|c|}{$\begin{array}{l}\text { ICD-11 use disorder (excl. harm to } \\
\text { others) }\end{array}$} \\
\hline & $\begin{array}{c}\text { No } \\
(\mathrm{n}=8,393)\end{array}$ & $\begin{array}{c}\text { Yes } \\
(\mathrm{n}=3,789)\end{array}$ & $\begin{array}{c}\text { No } \\
(\mathrm{n}=8,697)\end{array}$ & $\begin{array}{c}\text { Yes } \\
(\mathrm{n}=3,485)\end{array}$ & $\begin{array}{c}\text { No } \\
(\mathrm{n}=8,251)\end{array}$ & $\begin{array}{c}\text { Yes } \\
(\mathrm{n}=3,931)\end{array}$ & $\begin{array}{c}\text { No } \\
(\mathrm{n}=8,589)\end{array}$ & $\begin{array}{c}\text { Yes } \\
(\mathrm{n}=3,593)\end{array}$ \\
\hline DSM-IV use disorder & & & & & & & & \\
\hline No & - & - & 90.3 & 16.1 & 99.7 & 3.7 & 97.5 & 0.3 \\
\hline Yes & - & - & 9.7 & 83.9 & 0.3 & 96.3 & 2.5 & 99.7 \\
\hline Kappa & \multicolumn{2}{|c|}{-} & \multicolumn{2}{|c|}{0.71} & \multicolumn{2}{|c|}{0.97} & \multicolumn{2}{|c|}{0.95} \\
\hline DSM-5 use disorder & & & & & & & & \\
\hline No & 93.7 & 23.5 & - & - & 93.8 & 25.3 & 92.0 & 23.5 \\
\hline Yes & 6.3 & 76.5 & - & - & 6.2 & 74.7 & 8.0 & 76.5 \\
\hline Kappa & \multicolumn{2}{|c|}{0.71} & \multicolumn{2}{|c|}{ - } & \multicolumn{2}{|c|}{0.7} & \multicolumn{2}{|c|}{0.69} \\
\hline ICD-10 use disorder & & & & & & & & \\
\hline No & 98.4 & 0.6 & 89.2 & 15.5 & - & - & 96.0 & 0.7 \\
\hline Yes & 1.6 & 99.4 & 10.8 & 84.5 & - & - & 4.0 & 99.3 \\
\hline Карра & \multicolumn{2}{|c|}{0.97} & \multicolumn{2}{|c|}{0.7} & \multicolumn{2}{|c|}{-} & \multicolumn{2}{|c|}{0.93} \\
\hline ICD-11 use disorder* (excluding harm to others) & & & & & & & & \\
\hline No & 99.9 & 6.0 & 90.8 & 20.9 & 99.7 & 9.3 & - & - \\
\hline Yes & 0.1 & 94.0 & 9.2 & 79.1 & 0.3 & 90.7 & - & - \\
\hline Kappa & \multicolumn{2}{|c|}{0.95} & \multicolumn{2}{|c|}{0.69} & \multicolumn{2}{|c|}{0.93} & \multicolumn{2}{|c|}{-} \\
\hline Among people who have used cannabis... & \multicolumn{2}{|c|}{ DSM-IV use disorder } & \multicolumn{2}{|c|}{ DSM-5 use disorder } & \multicolumn{2}{|c|}{ ICD-10 use disorder } & \multicolumn{2}{|c|}{$\begin{array}{c}\text { ICD-11 use disorder (excl. harm to } \\
\text { others) }\end{array}$} \\
\hline$y$ & $\begin{array}{c}\text { No } \\
(\mathrm{n}=1,541)\end{array}$ & $\begin{array}{c}\text { Yes } \\
(\mathrm{n}=247)\end{array}$ & $\begin{array}{c}\text { No } \\
(\mathrm{n}=1,574)\end{array}$ & $\begin{array}{c}\text { Yes } \\
(\mathrm{n}=214)\end{array}$ & $\begin{array}{c}\text { No } \\
(\mathrm{n}=1,530)\end{array}$ & $\begin{array}{c}\text { Yes } \\
(\mathrm{n}=258)\end{array}$ & $\begin{array}{c}\text { No } \\
(\mathrm{n}=1,560)\end{array}$ & $\begin{array}{c}\text { Yes } \\
(\mathrm{n}=228)\end{array}$ \\
\hline \multicolumn{9}{|l|}{ DSM-IV use disorder } \\
\hline No & - & - & 94.8 & 26.3 & 100 & 5.6 & 98.9 & 1 \\
\hline Yes & - & - & 5.2 & 73.7 & 0 & 94.4 & 1.1 & 99 \\
\hline Kappa & \multicolumn{2}{|c|}{-} & & & & & & \\
\hline DSM-5 use disorder & & & & & & & & \\
\hline No & 96.5 & 35 & - & - & 96.8 & 37 & 96.2 & 33.1 \\
\hline Yes & 3.5 & 65 & - & - & 3.2 & 63 & 3.8 & 66.9 \\
\hline Kappa & & & & & & & & \\
\hline ICD-10 use disorder & & & & & & & & \\
\hline No & 99.1 & 0 & 94.2 & 24.3 & - & - & 98.1 & 0 \\
\hline Yes & 0.9 & 100 & 5.8 & 75.7 & - & - & 1.9 & 100 \\
\hline Kappa & & & & & & & & \\
\hline ICD-11 use disorder* (excluding harm to others) & & & & & & & & \\
\hline No & 99.9 & 7.5 & 95.4 & 29.1 & 100 & 11.8 & - & - \\
\hline Yes & 0.1 & 92.5 & 4.6 & 70.9 & 0 & 88.2 & - & - \\
\hline Kappa & & & & & & & & \\
\hline
\end{tabular}

1. Unweighted data - raw sample counts 


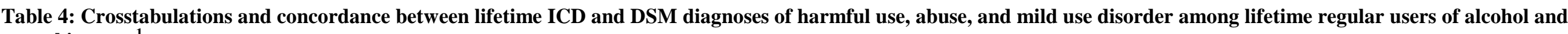
cannabis users ${ }^{1}$

\begin{tabular}{|c|c|c|c|c|c|c|c|c|}
\hline \multirow{2}{*}{$\begin{array}{l}\text { Among lifetime regular users of } \\
\text { alcohol... }\end{array}$} & \multicolumn{2}{|c|}{ DSM-IV abuse ${ }^{2}$} & \multicolumn{2}{|c|}{ DSM-5 mild use disorder ${ }^{3}$} & \multicolumn{2}{|c|}{ ICD-10 harmful use } & \multicolumn{2}{|c|}{$\begin{array}{c}\text { ICD-11 harmful use (excluding harm to } \\
\text { others) }\end{array}$} \\
\hline & $\begin{array}{c}\text { No } \\
(\mathrm{n}=9,273)\end{array}$ & $\begin{array}{c}\text { Yes } \\
(\mathrm{n}=2,909)\end{array}$ & $\begin{array}{c}\text { No } \\
(\mathrm{n}=10,446)\end{array}$ & $\begin{array}{c}\text { Yes } \\
(\mathrm{n}=1,736)\end{array}$ & $\begin{array}{c}\text { No } \\
(\mathrm{n}=9,079)\end{array}$ & $\begin{array}{c}\text { Yes } \\
(\mathrm{n}=3,103)\end{array}$ & $\begin{array}{c}\text { No } \\
(\mathrm{n}=9,531) \\
\end{array}$ & $\begin{array}{c}\text { Yes } \\
(\mathrm{n}=2,651)\end{array}$ \\
\hline DSM-IV abuse & & & & & & & & \\
\hline No & - & - & 84.0 & 30.0 & 99.4 & 7.6 & 97.0 & 0.9 \\
\hline Yes & - & - & 16.0 & 70.0 & 0.6 & 92.4 & 3.0 & 99.1 \\
\hline Kappa & \multicolumn{2}{|c|}{$=$} & \multicolumn{2}{|c|}{0.42} & \multicolumn{2}{|c|}{0.94} & \multicolumn{2}{|c|}{$\mathbf{0 . 9 3}$} \\
\hline \multicolumn{9}{|l|}{ DSM-5 mild use disorder } \\
\hline No & 94.4 & 57.8 & - & - & 94.7 & 59.1 & 93.1 & 59.0 \\
\hline Yes & 5.6 & 42.2 & - & - & 5.3 & 40.9 & 6.9 & 41.0 \\
\hline Kappa & \multicolumn{2}{|c|}{0.42} & \multicolumn{2}{|c|}{-} & \multicolumn{2}{|c|}{0.41} & \multicolumn{2}{|c|}{$\mathbf{0 . 3 9}$} \\
\hline \multicolumn{9}{|l|}{ ICD-10 harmful use } \\
\hline No & 97.5 & 1.8 & 82.6 & 28.0 & - & - & 95.3 & 0.5 \\
\hline Yes & 2.5 & 98.2 & 17.4 & 72.0 & - & - & 4.7 & 99.5 \\
\hline Kappa & \multicolumn{2}{|c|}{0.94} & \multicolumn{2}{|c|}{0.41} & \multicolumn{2}{|c|}{-} & \multicolumn{2}{|c|}{0.9} \\
\hline \multicolumn{9}{|l|}{$\begin{array}{l}\text { ICD-11 harmful use (excluding harm to } \\
\text { others }\end{array}$} \\
\hline No & 99.8 & 10.0 & 85.2 & 38.3 & 99.9 & 14.9 & - & - \\
\hline Yes & 0.2 & 90.0 & 14.8 & 61.7 & 0.1 & 85.1 & - & - \\
\hline Kappa & \multicolumn{2}{|c|}{0.93} & \multicolumn{2}{|c|}{0.39} & \multicolumn{2}{|c|}{0.9} & \multicolumn{2}{|c|}{-} \\
\hline $\begin{array}{l}\text { Among people who have used } \\
\text { cannabis... }\end{array}$ & \multicolumn{2}{|c|}{ DSM-IV abuse $^{1}$} & \multicolumn{2}{|c|}{ DSM-5 mild use disorder ${ }^{2}$} & \multicolumn{2}{|c|}{ ICD-10 harmful use } & \multicolumn{2}{|c|}{$\begin{array}{c}\text { ICD-11 harmful use (excluding harm to } \\
\text { others) }\end{array}$} \\
\hline ( & $\begin{array}{c}\text { No } \\
(\mathrm{n}=1,595)\end{array}$ & $\begin{array}{c}\text { Yes } \\
(\mathrm{n}=193) \\
\end{array}$ & $\begin{array}{c}\text { No } \\
(\mathrm{n}=1,672)\end{array}$ & $\begin{array}{c}\text { Yes } \\
(\mathrm{n}=116)\end{array}$ & $\begin{array}{c}\text { No } \\
(\mathrm{n}=1,589)\end{array}$ & $\begin{array}{c}\text { Yes } \\
(\mathrm{n}=199)\end{array}$ & $\begin{array}{c}\text { No } \\
(\mathrm{n}=1,619) \\
\end{array}$ & $\begin{array}{c}\text { Yes } \\
(\mathrm{n}=169) \\
\end{array}$ \\
\hline \multicolumn{9}{|l|}{ DSM-IV abuse } \\
\hline No & - & - & 93.0 & 38.5 & 99.8 & 7.8 & 98.7 & 2.2 \\
\hline Yes & - & - & 7.0 & 61.5 & 0.2 & 92.2 & 1.3 & 97.8 \\
\hline Kappa & & & & & & & & \\
\hline DSM-5 mild use disorder & & & & & & & & \\
\hline No & 97.4 & 63.8 & - & - & 97.4 & 65.7 & 97.0 & 63.9 \\
\hline Yes & 2.6 & 36.2 & - & - & 2.6 & 34.3 & 3.0 & 36.1 \\
\hline Kappa & & & & & & & & \\
\hline ICD-10 harmful use & & & & & & & & \\
\hline No & 99.1 & 2.0 & 92.4 & 38.1 & - & - & 98.2 & - \\
\hline Yes & 0.9 & 98.0 & 7.6 & 61.9 & - & - & 1.8 & 100 \\
\hline Kappa & & & & & & & & \\
\hline
\end{tabular}


ICD-11 harmful use (excluding harm to others

No

Yes

Kappa

Unweighted data - raw sample counts

Abuse without dependence

DSM-5 mild disorder only (exclude moderate or severe)

Pooled data excludes Portugal who did not assess illicit drug use disorders. 


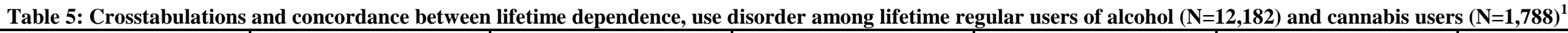

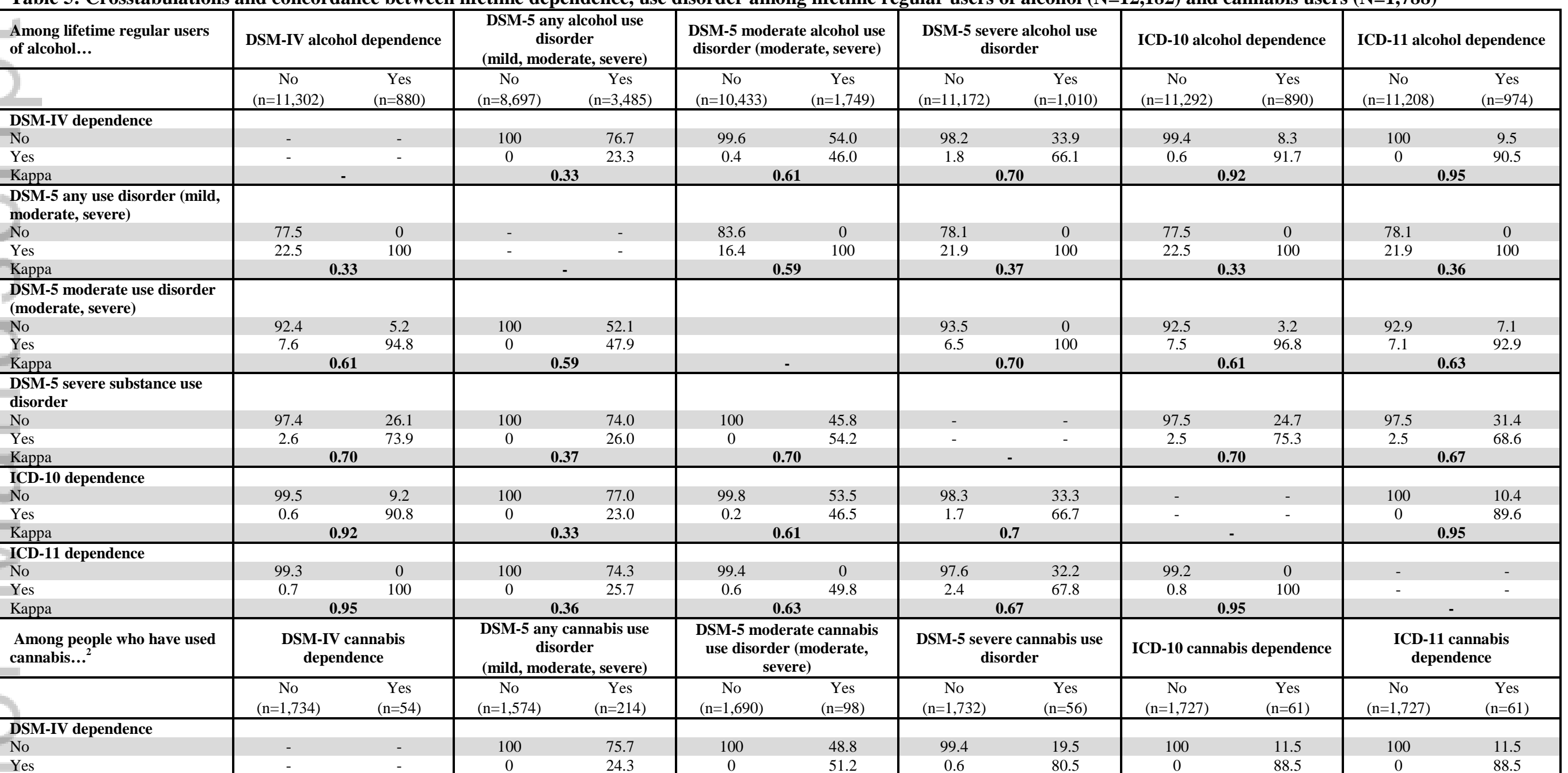

This article is protected by copyright. All rights reserved. 


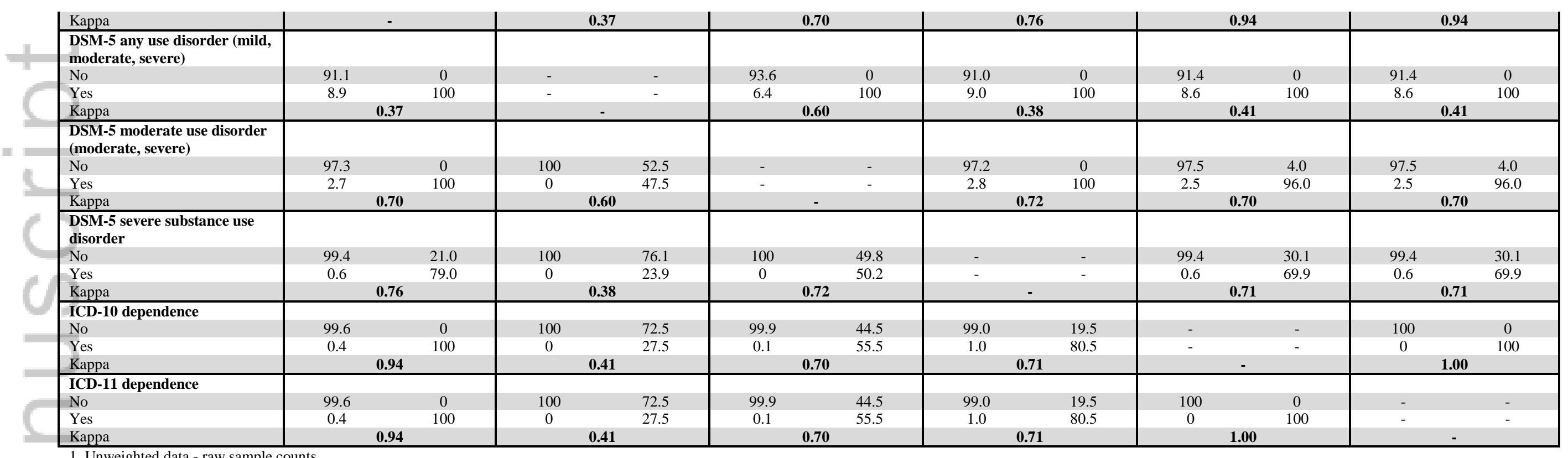

1. Unweighted data - raw sample counts

2. Pooled data excludes Portugal who did not assess illicit drug use disorders. 


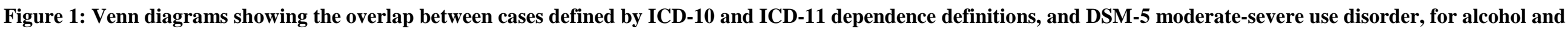
cannabis

Alcohol

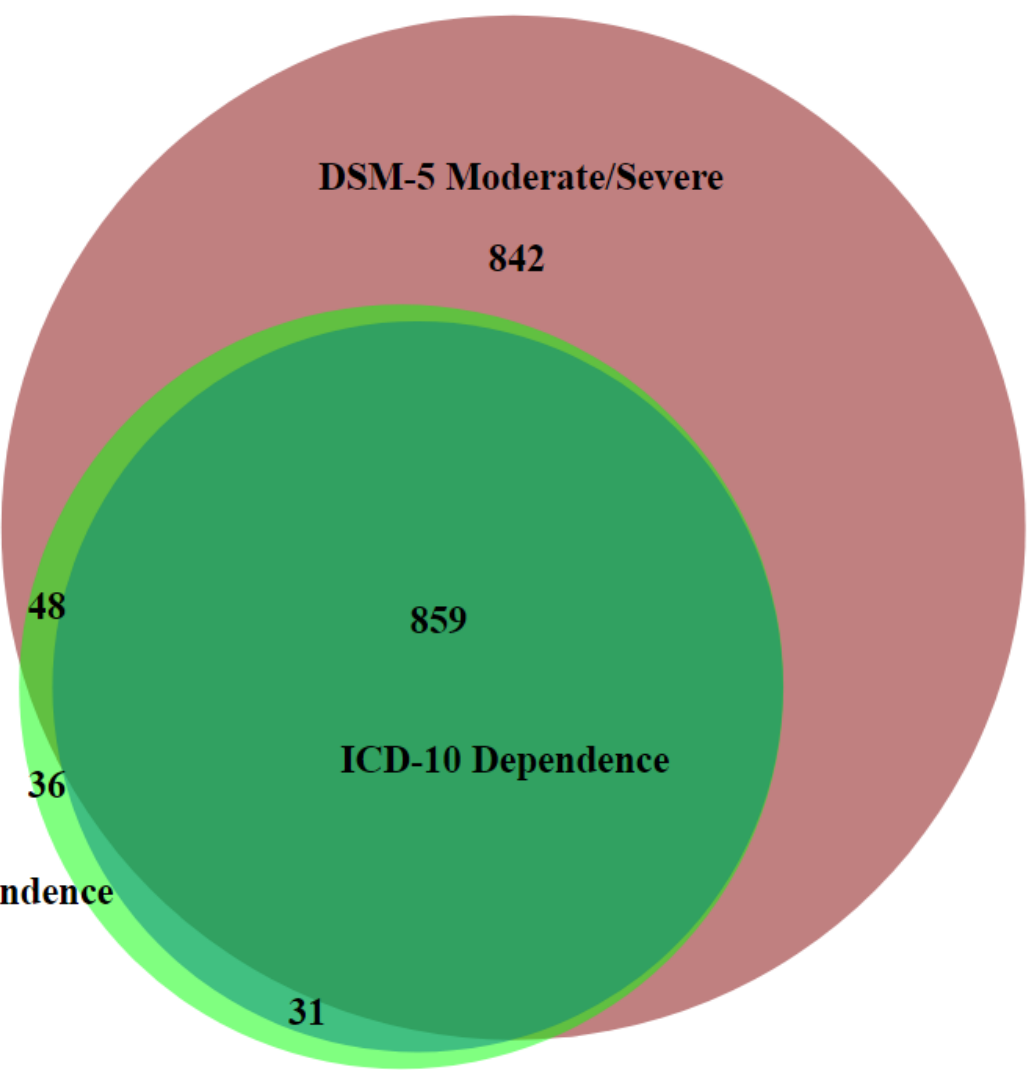

\section{Cannabis}

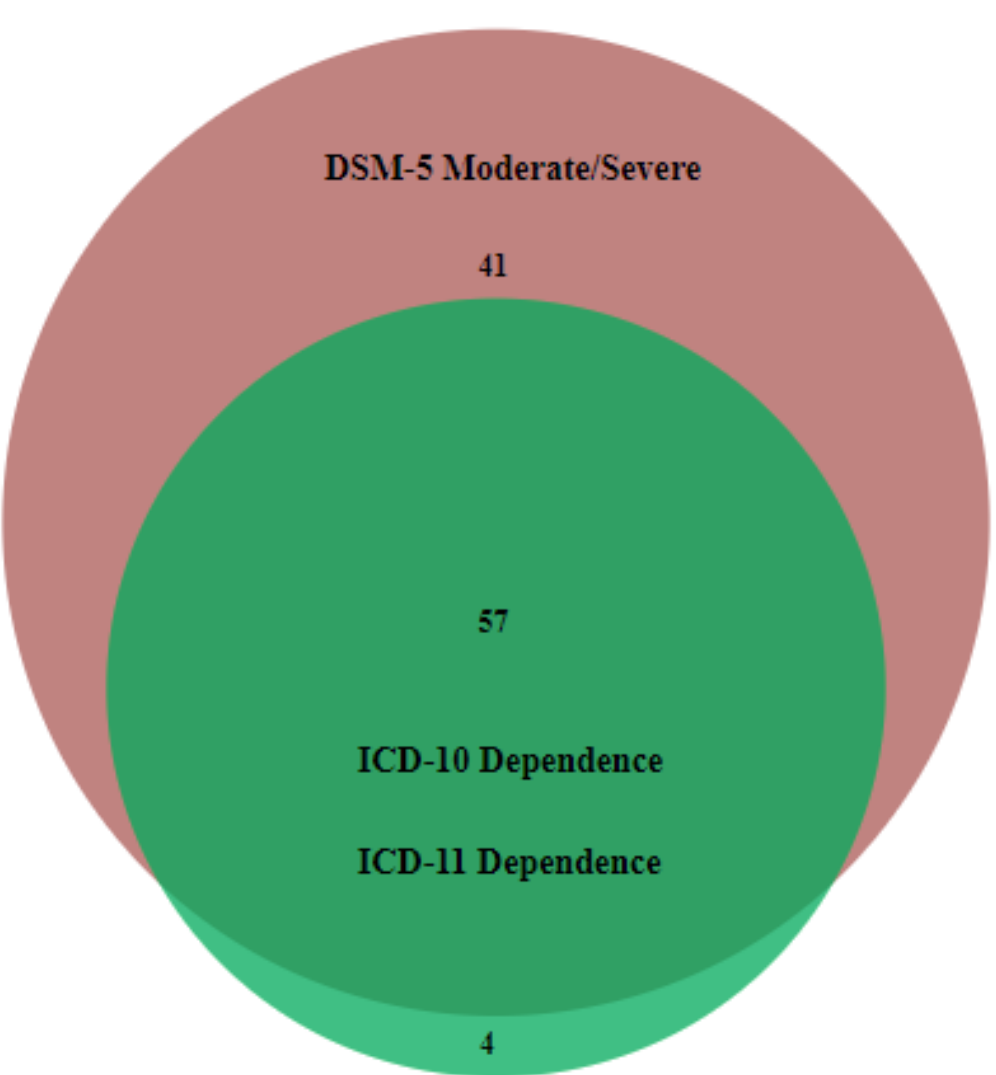

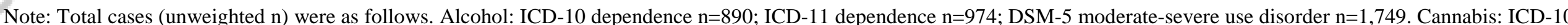
dependence $n=61$; ICD-11 dependence $n=61$; DSM-5 moderate-severe use disorder $n=98$. Diagrams produced in BioVenn ${ }^{47}$. 
Table 6: Diagnostic crosswalks of ICD-11 diagnostic categories with ICD-10 and DSM-5, among lifetime regular alcohol users and cannabis users ${ }^{1}$

\begin{tabular}{|c|c|c|c|c|c|c|}
\hline & \multicolumn{3}{|c|}{ Alcohol } & \multicolumn{3}{|c|}{ Cannabis } \\
\hline & ICD-11 no diagnosis & ICD-11 harmful use ${ }^{1,2}$ & ICD-11 dependence & ICD-11 no diagnosis & ICD-11 harmful use $e^{1,2}$ & ICD-11 dependence \\
\hline \multirow{2}{*}{ ICD-10 no diagnosis } & 8227 & 0 & 24 & 1530 & 0 & 0 \\
\hline & $(67.53 \%)$ & $(0 \%)$ & $(0.2 \%)$ & $(85.57 \%)$ & $(0 \%)$ & $(0 \%)$ \\
\hline \multirow{2}{*}{ ICD-10 harmful use ${ }^{2}$} & 362 & 2619 & 60 & 30 & 167 & 0 \\
\hline & $(2.97 \%)$ & $(21.5 \%)$ & $(0.49 \%)$ & $(1.68 \%)$ & $(9.34 \%)$ & $(0 \%)$ \\
\hline \multirow{2}{*}{ ICD-10 dependence } & 0 & 0 & 890 & 0 & 0 & 61 \\
\hline & $(0 \%)$ & $(0 \%)$ & $(7.31 \%)$ & $(0 \%)$ & $(0 \%)$ & $(3.41 \%)$ \\
\hline & ICD-11 no diagnosis & ICD-11 harmful use $\mathrm{I}^{1,2}$ & ICD-11 dependence & ICD-11 no diagnosis & ICD-11 harmful use $e^{1,2}$ & ICD-11 dependence \\
\hline \multirow{2}{*}{ DSM-5 no diagnosis } & 7868 & 829 & 0 & 1500 & 74 & 0 \\
\hline & $(64.59 \%)$ & $(6.81 \%)$ & $(0 \%)$ & $(83.89 \%)$ & $(4.14 \%)$ & $(0 \%)$ \\
\hline \multirow{2}{*}{ DSM-5 mild } & 624 & 1045 & 67 & 53 & 59 & 4 \\
\hline & $(5.12 \%)$ & $(8.58 \%)$ & $(0.55 \%)$ & $(2.96 \%)$ & $(3.3 \%)$ & $(0.22 \%)$ \\
\hline \multirow{2}{*}{ DSM-5 moderate } & 81 & 442 & 216 & 5 & 22 & 15 \\
\hline & $(0.66 \%)$ & $(3.63 \%)$ & $(1.77 \%)$ & $(0.28 \%)$ & $(1.23 \%)$ & $(0.84 \%)$ \\
\hline \multirow{2}{*}{ DSM-5 severe } & 16 & 303 & 691 & 2 & 12 & 42 \\
\hline & $(0.13 \%)$ & $(2.49 \%)$ & $(5.67 \%)$ & $(0.11 \%)$ & $(0.67 \%)$ & $(2.35 \%)$ \\
\hline
\end{tabular}

1. Unweighted data (percent within substance sample) - raw sample counts.

2. Without harm to others

3. Without ever an occurrence of dependence

This article is protected by copyright. All rights reserved. 
Table 7: Demographic and clinical correlates, and features of disorder, among those meeting varying definitions of alcohol and cannabis use disorders

\begin{tabular}{|c|c|c|c|c|c|c|c|c|}
\hline \multicolumn{9}{|c|}{ Among those classified as meeting criteria for alcohol use disorders defined via...... } \\
\hline 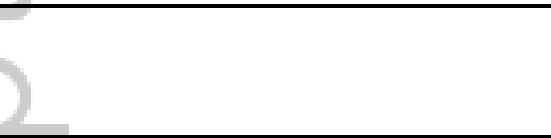 & 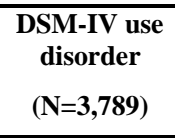 & $\begin{array}{c}\text { DSM-IV } \\
\text { dependence } \\
(\mathrm{N}=\mathbf{8 8 0})\end{array}$ & $\begin{array}{c}\text { DSM-5 use } \\
\text { disorder } \\
(\mathrm{N}=\mathbf{3}, 485)\end{array}$ & $\begin{array}{c}\text { DSM-5 } \\
\text { moderate/severe } \\
\text { use disorder } \\
(\mathrm{N}=1,749)\end{array}$ & $\begin{array}{c}\text { ICD-10 use } \\
\text { disorder } \\
(\mathbf{N}=\mathbf{3 , 9 3 1})\end{array}$ & $\begin{array}{l}\text { ICD-10 dependence } \\
\qquad(\mathrm{N}=\mathbf{8 9 0})\end{array}$ & $\begin{array}{c}\text { ICD-11 use } \\
\text { disorder } \\
(\mathrm{N}=3,593)\end{array}$ & $\begin{array}{l}\text { ICD-11 dependence } \\
\qquad(\mathrm{N}=974)\end{array}$ \\
\hline History and course of use disorder & & & & & & & & \\
\hline Median age of onset of regular use ${ }^{1,2}$ & 17 & 16 & 17 & 16 & 17 & 16 & 17 & 16 \\
\hline Median age of onset of first symptom ${ }^{2,3}$ & 20 & 20 & 20 & 20 & 20 & 20 & 20 & 20 \\
\hline$\%$ Past 12 month symptoms & $22.91(0.96)$ & $36.26(1.95)$ & $24.34(1.02)$ & $27.48(1.56)$ & $22.63(0.94)$ & $37.17(2.01)$ & $23.44(1.01)$ & $36.16(1.89)$ \\
\hline$\%$ Family history of problematic use ${ }^{2}$ & $42.74(1.15)$ & $54.8(1.95)$ & $45.33(1.26)$ & $51.65(1.7)$ & $42.56(1.13)$ & $53.58(2.04)$ & $42.72(1.22)$ & $54.12(1.94)$ \\
\hline \% Lifetime hospital treatment for mental/SUD ${ }^{2}$ & $4.57(0.43)$ & $14.32(1.53)$ & $5.67(0.52)$ & $9.29(0.87)$ & $4.58(0.43)$ & $14.35(1.53)$ & $4.82(0.46)$ & $13.15(1.41)$ \\
\hline$\%$ Past year treatment for SUD ${ }^{2}$ & $3.85(0.39)$ & $14.15(1.51)$ & $4.72(0.49)$ & $7.93(0.81)$ & $3.75(0.38)$ & $14.03(1.52)$ & $4.07(0.42)$ & $12.81(1.39)$ \\
\hline Demographic variables & & & & & & & & \\
\hline Median age & 40 & 42 & 39 & 39 & 40 & 41 & 39 & 41 \\
\hline$\%$ Female & $22.39(0.92)$ & $22.61(1.68)$ & $25.37(1.08)$ & $20.39(1.17)$ & $22.45(0.9)$ & $22.18(1.89)$ & $21.34(0.9)$ & $22.73(1.76)$ \\
\hline$\%$ Completed high school & $68.34(1.05)$ & $61.46(1.88)$ & $67.78(1.18)$ & $63.4(1.51)$ & $68.39(1.04)$ & $60.72(1.89)$ & $68.7(1.08)$ & $61.14(1.85)$ \\
\hline$\%$ Unemployed/not in labour force & $12.71(0.85)$ & $19.93(1.63)$ & $13.24(0.91)$ & $18.53(1.42)$ & $12.66(0.84)$ & $18.99(1.51)$ & $12.95(0.87)$ & $19.46(1.53)$ \\
\hline$\%$ Married & $50.23(1.26)$ & $46.72(2.32)$ & $48.58(1.31)$ & $45.15(1.79)$ & $50.99(1.24)$ & $46.61(2.37)$ & $49.57(1.31)$ & $46.74(2.24)$ \\
\hline Clinical correlates & & & & & & & & \\
\hline \% Lifetime generalised anxiety disorder & $9.47(0.68)$ & $17.63(1.77)$ & $10.97(0.74)$ & $14.8(1.23)$ & $9.33(0.67)$ & $18.19(1.79)$ & $9.03(0.69)$ & $17.14(1.68)$ \\
\hline \% Lifetime affective disorder & $24.63(0.98)$ & $38.54(2.13)$ & $27.35(1.05)$ & $35.09(1.61)$ & $24.24(0.95)$ & $38.42(1.96)$ & $24.66(1.03)$ & $36.89(1.97)$ \\
\hline \% Lifetime cannabis abuse ${ }^{4,5}$ & $12.06(0.79)$ & $11.51(1.37)$ & $12.46(0.84)$ & $15.05(1.42)$ & $11.73(0.77)$ & $11.86(1.37)$ & $12.42(0.83)$ & $12.21(1.49)$ \\
\hline \% Lifetime cannabis dependence ${ }^{4,5}$ & $6.48(0.63)$ & $18.81(2.09)$ & $7.37(0.7)$ & $12.11(1.16)$ & $6.4(0.62)$ & $18.65(2.14)$ & $6.63(0.65)$ & $17.88(1.94)$ \\
\hline & & Imong those cl & ed as meeting criteria & or cannabis use disor & defined via..... & & & \\
\hline 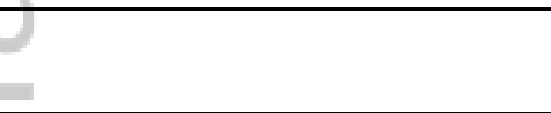 & $\begin{array}{l}\text { DSM-IV use } \\
\text { disorder } \\
(\mathrm{N}=247)\end{array}$ & $\begin{array}{c}\text { DSM-IV } \\
\text { dependence } \\
(\mathrm{N}=54)\end{array}$ & $\begin{array}{l}\text { DSM-5 use disorder } \\
\qquad(\mathrm{N}=214)\end{array}$ & $\begin{array}{c}\text { DSM-5 } \\
\text { moderate/severe } \\
\text { use disorder }(\mathrm{N}=98)\end{array}$ & $\begin{array}{l}\text { ICD-10 use } \\
\text { disorder } \\
(\mathrm{N}=258)\end{array}$ & $\begin{array}{l}\text { ICD-10 dependence } \\
\qquad(\mathrm{N}=61)\end{array}$ & $\begin{array}{l}\text { ICD-11 use } \\
\text { disorder } \\
(\mathrm{N}=228)\end{array}$ & $\begin{array}{c}\text { ICD-11 dependence } \\
(\mathbf{N}=61)\end{array}$ \\
\hline History and course of use disorder & & & & & & & & \\
\hline Median age of onset of use & 17 & 16 & 16 & 16 & 17 & 16 & 17 & 16 \\
\hline Median age of onset of first symptom ${ }^{3}$ & 19 & 19 & 19 & 19 & 19 & 19 & 19 & 19 \\
\hline$\%$ Past 12 month symptoms & $7.32(1.39)$ & $15.7(4.44)$ & $7.59(1.52)$ & $11.16(2.92)$ & $7.08(1.33)$ & $14.62(4.09)$ & $7.14(1.41)$ & $14.62(4.09)$ \\
\hline$\%$ Family history of problematic use ${ }^{2}$ & $54.39(3.64)$ & $61.66(6.66)$ & $59.44(4.27)$ & $59.45(6.43)$ & $52.93(3.81)$ & $59.76(7.2)$ & $53.98(3.93)$ & $59.76(7.2)$ \\
\hline$\%$ Lifetime hospital treatment for mental/SUD ${ }^{2}$ & $1.37(0.59)$ & $4.47(2.62)$ & $2.69(1.00)$ & $3.12(1.39)$ & $3.48(2.19)$ & $3.96(2.33)$ & $1.2(0.59)$ & $3.96(2.33)$ \\
\hline$\%$ Past year treatment for SUD & $4.45(1.23)$ & $10.42(4.48)$ & $5.34(1.49)$ & $8.18(2.86)$ & $4.2(1.17)$ & $9.24(4.03)$ & $4.76(1.32)$ & $9.24(4.03)$ \\
\hline Demographic variables & & & & & & & & \\
\hline Median age & 34 & 30 & 34 & 29 & 34 & 31 & 34 & 31 \\
\hline$\%$ Female & $29.2(3.28)$ & $34.6(7.47)$ & $29.55(3.56)$ & $24.1(5.31)$ & $28.55(3.15)$ & $34.35(7.18)$ & $28.53(3.3)$ & $34.35(7.18)$ \\
\hline$\%$ Completed high school & $71.94(3.3)$ & $72.85(6.23)$ & $66.21(3.76)$ & $67.44(5.61)$ & $71.58(3.23)$ & $71.95(5.97)$ & $72.47(3.47)$ & $71.95(5.97)$ \\
\hline \% Unemployed/not in labour force & $10.15(2.79)$ & $10.57(4.57)$ & $13.56(2.12)$ & $14.15(1.45)$ & $11.89(3.27)$ & $9.36(4.08)$ & $10.4(2.97)$ & $9.36(4.08)$ \\
\hline
\end{tabular}

This article is protected by copyright. All rights reserved. 


\begin{tabular}{|c|c|c|c|c|c|c|c|c|}
\hline$\%$ Married & $44.24(3.68)$ & $32.45(6.11)$ & $36.45(3.51)$ & $33.57(5.21)$ & $43.0(3.68)$ & $36.19(7.05)$ & $44.34(3.89)$ & $36.19(7.05)$ \\
\hline \multicolumn{9}{|l|}{ Clinical correlates } \\
\hline \% Lifetime generalised anxiety disorder & $9.07(1.99)$ & $9.07(3.41)$ & $7.53(1.55)$ & $8.79(2.43)$ & $10.73(2.7)$ & $8.03(3.1)$ & $9.17(2.1)$ & $8.03(3.1)$ \\
\hline$\%$ Lifetime affective disorder & $23.94(3.23)$ & $31.18(7.33)$ & $22.8(3.22)$ & $24.42(5.29)$ & $25.26(3.62)$ & $34.04(6.85)$ & $24.37(3.45)$ & $34.04(6.85)$ \\
\hline$\%$ Lifetime alcohol abuse $^{4}$ & $41.25(3.75)$ & $20.18(7.56)$ & $39.22(4.42)$ & $41.88(6.67)$ & $39.6(3.73)$ & $27.17(8.11)$ & $42.65(3.99)$ & $27.17(8.11)$ \\
\hline$\%$ Lifetime alcohol dependence ${ }^{4}$ & $18.96(3.52)$ & $38.65(6.67)$ & $16.86(2.43)$ & $24.92(4.14)$ & $20.47(3.74)$ & $34.22(6.36)$ & $18.2(3.74)$ & $34.22(6.36)$ \\
\hline
\end{tabular}

SUD = substance use disorder

1. Regular use is defined here as 12 standard drinks in a year

2. Excludes respondents with unknown or not-stated values

3. First symptom includes abuse or dependence problem. Does not exclude symptoms that are not part of a specific disorder definition (e.g. legal criterion in DSM-IV).

4. DSM-IV diagnoses.

5. Estimates exclude Portugal who did not assess illicit drug disorders. 


\section{University Library}

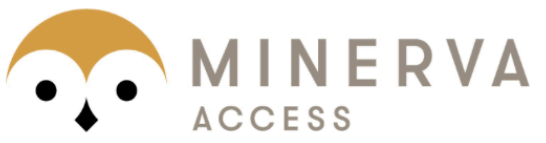

A gateway to Melbourne's research publications

Minerva Access is the Institutional Repository of The University of Melbourne

\section{Author/s:}

Degenhardt, L;Bharat, C;Bruno, R;Glantz, MD;Sampson, NA;Lago, L;Aguilar-Gaxiola, S;Alonso, J;Andrade, LH;Bunting, B;Caldas-de-Almeida, JM;Cia, AH;Gureje, O;Karam, EG;Khalaf, M;McGrath, JJ;Moskalewicz, J;Lee, S;Mneimneh, Z;Navarro-Mateu, F;Sasu, CC;Scott, K;Torres, Y;Poznyak, V;Chatterji, S;Kessler, RC;WHO World Mental Health Survey Collaborators,

Title:

Concordance between the diagnostic guidelines for alcohol and cannabis use disorders in the draft ICD-11 and other classification systems: analysis of data from the WHO's World Mental Health Surveys.

\section{Date:}

2019-03

\section{Citation:}

Degenhardt, L., Bharat, C., Bruno, R., Glantz, M. D., Sampson, N. A., Lago, L., AguilarGaxiola, S., Alonso, J., Andrade, L. H., Bunting, B., Caldas-de-Almeida, J. M., Cia, A. H., Gureje, O., Karam, E. G., Khalaf, M., McGrath, J. J., Moskalewicz, J., Lee, S., Mneimneh, Z. ,... WHO World Mental Health Survey Collaborators, (2019). Concordance between the diagnostic guidelines for alcohol and cannabis use disorders in the draft ICD-11 and other classification systems: analysis of data from the WHO's World Mental Health Surveys.. Addiction, 114 (3), pp.534-552. https://doi.org/10.1111/add.14482.

Persistent Link:

http://hdl.handle.net/11343/284700 